\title{
The three-dimensional arrangement of the mineralized collagen fibers in elephant ivory and its relation to mechanical and optical properties
}

\author{
Albéric M. ${ }^{1}$, Gourrier A. ${ }^{2,3}$, Wagermaier W. ${ }^{1}$, Fratzl P. ${ }^{1}$ and Reiche I. ${ }^{1,4-6^{*}}$ \\ ${ }^{1}$ Department of Biomaterials, Max-Planck-Institute of Colloids and Interfaces, Potsdam, Germany \\ ${ }^{2}$ Univ. Grenoble Alpes, CNRS, LIPhy, 38000 Grenoble, France \\ ${ }^{3}$ European Synchrotron Radiation Facility, Grenoble, France \\ ${ }^{4}$ Rathgen-Forschungslabor, Staatliche Museen zu Berlin, Stiftung Preußischer Kulturbesitz, Berlin, Germany \\ ${ }^{5}$ present address: Chimie-Paristech, PSL, Research University, CNRS, Institut de Recherche Chimie-Paris (IRCP), UMR \\ 8247, F-75005 Paris, France \\ ${ }^{6}$ present address: Centre de recherche et de restauration des musées de France (C2RMF), F-75001 Paris, France \\ * Corresponding author: I.Reiche@smb.spk-berlin.de/ina.reiche@chimie-paristech.fr (+49-30-266 427101/00)
}

\begin{abstract}
Elephant tusks are composed of dentin or ivory, a hierarchical and composite biological material made of mineralized collagen fibers (MCF). The specific arrangement of the MCF is believed to be responsible for the optical and mechanical properties of the tusks. Especially the MCF organization likely contributes to the formation of the bright and dark checkerboard pattern observed on polished sections of tusks (Schreger pattern). Yet, the precise structural origin of this optical motif is still controversial. We hereby address this issue using complementary analytical methods (small and wide angle X-ray scattering, cross-polarized light microscopy and scanning electron microscopy) on elephant ivory samples and show that MCF orientation in ivory varies from the outer to the inner part of the tusk. An external cohesive layer of MCF with fiber direction perpendicular to the tusk axis wraps the mid-dentin region, where the MCF are oriented mainly along the tusk axis and arranged in a plywood-like structure with fiber orientations oscillating in a narrow angular range. This particular oscillating-plywood structure of the MCF and the birefringent properties of the collagen fibers, likely contribute to the emergence of the Schreger pattern, one of the most intriguing macroscopic optical patterns observed in mineralized tissues and of great importance for authentication issues in archeology and forensic sciences.
\end{abstract}

Keywords: Elephant ivory, mineralized collagen fibers, oscillated-plywood structure, small and wide angle Xray scattering, cross-polarized light microscopy, scanning electron microscopy. 


\section{Introduction.}

Elephantoidea (elephant and mammoth) tusk dentin or ivory is a valuable biological material, which has been shaped since prehistoric times into precious artefacts taking advantage of its aesthetic properties (fineness of grain, luster and tactile appeal once polished) [1-4]. Ivory was preferentially used for the production of highvalue and symbolic objects (figurines, beads, ornaments, etc.) $[2,4-6]$ whereas bone and antler were preferred for the production of utilitarian tools and weapons $[1,7]$. Understanding the technological processes developed by past societies to manufacture precious object from ivory is therefore the focus of many researches, especially relevant for art, archaeology and the art market. In order to do so, the specific patterns of fracture in Elephantoidea ivory and its unique macroscopic optical motif, the Schreger pattern [8], are used as diagnostic characteristics to identify ivory among the osseous industry materials at archeological sites and among art objects. On transverse sections (perpendicular to the tusk axis) of Elephantoidea tusks, the Schreger pattern consists of an arrangement of staggered bright and dark rhomboids $\left(\sim 0.5 \times 0.5 \mathrm{~mm}^{2}\right)$ that leads to the emergence of the Schreger lines that radiate clockwise and anti-clockwise from the tusk axis (Fig.1 A). Despite its great importance, the structural origin of the motif is still controversial and the physical phenomenon responsible for the black and white contrast of the pattern is unknown.

Elephant tusks are upper incisors, which initial teeth functions (mastication, cutting, gnawing) were lost to the benefit of other purposes: digging, carrying heavy load and fighting [9]. Therefore, elephant tusks are subjected to mechanical forces more similar to those experienced by bones (bending or/and bearing load $[10,11]$ ) and antlers (bending and impact load [12]) than by most teeth (compression [13]). Elephant ivory is thus a biological material close to teeth dentin, bones and antlers in terms of mechanical properties and hence, in terms of chemical and structural characteristics. Indeed, at the micro-level, elephant dentin retains a tubular network as in teeth and exhibits a similar arrangement of the mineralized collagen fibers (MCF) to this of lamellar bones.

Many studies attribute the formation of the Schreger pattern to the 3D arrangement of the dentinal tubules [1417], which are remaining evidences of the odontoblast cell path during ivory growth as well as during dentinogenesis [18]. However, the Schreger pattern could also result from specific orientation of the MCF as suggested by [19].

The MCF network is described in terms of the MCF orientations, which refers to the orientation of the long axis of the MCF in three-dimension. In lamellar bones (main tissue type of mammal bones), layers of parallel MCF are staggered in a plywood-like arrangement [20]. Each MCF layer has a distinct orientation and is tilted with respect to the next layer either continuously (twisted-plywood [21], oscillating-plywood [22]) or discretely (orthogonal-plywood [23], asymmetrical rotated-plywood [20], helical plywood [24]) (for review see [25]). In ivory, the MCF were proposed to arrange in a rotated-plywood like structure [19] with two orthogonal axes of rotation oriented along a set of intersecting ridges radiating respectively clockwise and anti-clockwise from the tusk axis [19] (see Supplementary Appendix B Fig. 1 for a scheme of the model proposed in [19]). This complex arrangement was suggested to be at the origin of the Schreger lines.

Finally, at the nanoscale, ivory is composed of staggered collagen molecules and Mg-rich carbonated hydroxyapatite nano-crystals (Mg-carb-HAP) constituting the mineralized fibrils that are together arranged into the MCF [19, 26-29]. As for many other biological materials [10, 30-34], the mechanical properties of elephant ivory [27, 35-37] originate from its nano-composite nature and hierarchical structure from macro- down to nanoscale.

In this paper, we revisit the structural arrangement of MCF in elephant tusk dentin (ivory), which may contribute to both the mechanical properties of tusks [27, 35] and the formation of the unique Schreger pattern of Elephantoidea ivory [19]. Using a multimodal analytical approach, well established for the study of MCF in biological tissues [11, 13, 24, 38-40], we investigated the MCF arrangement of elephant ivory within a volume 
of dentin from cement to pulp (Fig. 1. B). Small- and wide-angle X-ray scattering (SAXS/WAXS) measurements and cross-polarized light microscopy (CPL) observations respectively allowed quantifying the degree of organization and the orientation of the MCF and relating the Schreger pattern to the MCF orientation. Additionally scanning electron microscopy (SEM) was performed. A 3D model of the MCF network is proposed and the structure-properties relationships are further discussed in terms of optical (origin of the Schreger pattern) and mechanical properties.
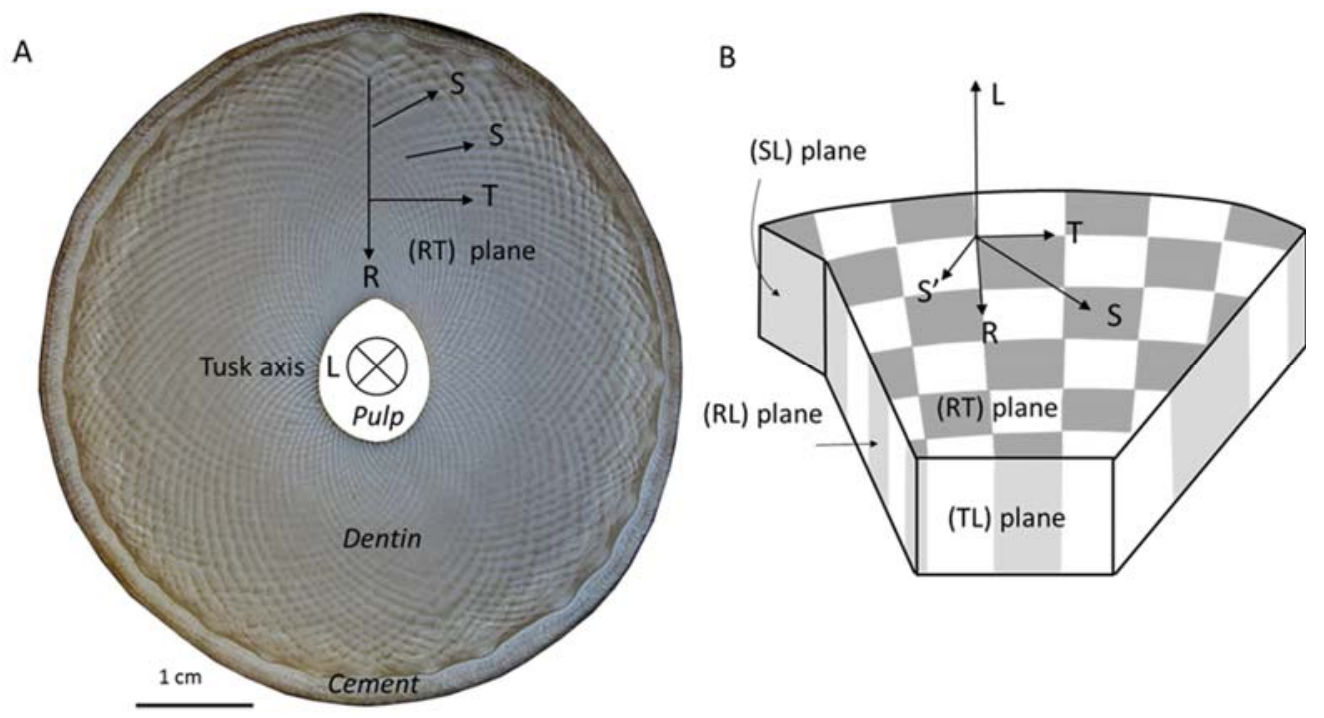

Fig.1: Schreger pattern and system of reference.

A) Polished transverse section of an elephant tusk showing the checkerboard Schreger pattern with the system of reference indicated: the longitudinal (L), tangential (T), radial (R) and Schreger (S) axis and B) scheme in 3D of the four studied planes: the transverse (RT), longitudinal (RL), tangential (TL) and Schreger (SL) planes.

\section{Methods.}

Material: Two tusks obtained from customs seizures and identified as originating from African elephants (Loxodonta africana) were studied. The system of reference used in this paper considers the longitudinal (RL), transverse (RT), tangential (TL) and Schreger (SL) planes (Fig. 1). This coordinate system can be related to both the ivory growth direction and the macroscopic Schreger pattern. Indeed, elephant tusk has a conical growth, in two directions: radial and longitudinal. Therefore, the longitudinal (L) axis (tusk axis) refers to the longitudinal growth, the radial $(\mathrm{R})$ axis relates to the radial growth and the tangential (TL) plane to the mineralization growth plane. In addition, the $(\mathrm{R})$ and $(\mathrm{T})$ directions are perpendicular to the rhomboids of the checkerboard pattern and the $\mathrm{S}$ direction is diagonal to them (Fig. 1). The three main parts of the tusk: the dentin, the cement and the internal canal (the pulp cavity) are indicated on the (RT) cross-section of Fig. 1A, on which the checkerboard pattern and the associated Schreger lines are observed.

Sample preparation: Sections $(200 \mu \mathrm{m}$ thick) of the elephant tusks were cut with a diamond saw (Leica SP1600 saw microtome) using water as lubricant. For SAXS measurements, thick sections were reduced down to $70 \mu \mathrm{m}$ in thickness by grinding ( $\mathrm{SiC} 2000,10 \mu \mathrm{m}$, Logitech PM5 Precision Lapping and Polishing machine). For cross-polarized light (CPL) observations, the thin sections were demineralized in order to eliminate the apatite birefringence and screen the $\mathrm{CF}$ orientation only. They were demineralized in $0.5 \mathrm{M}$ ethylene diamine tetra-acetic acid (EDTA) adjusted to $\mathrm{pH} 7.4$ by $\mathrm{NaOH}$ during two weeks at $25^{\circ} \mathrm{C}$ under agitation on a rocking table (see Appendix A for the proof of efficient removal of the crystals). Crossed PL observations were made on rehydrated thin sections. Fractured sections were obtained and carbon-coated by vacuum evaporation (SCD 004, Balzers, Lichtenstein) prior to SEM examinations. 
Small- and wide- angle $\mathrm{X}$-ray scattering experiments: Small- and wide- angle X-ray scattering (SAXS/WAXS) experiments were performed at the mySpot beamline at the BESSY II synchrotron radiation facility (HZB, Helmholtz-Zentrum Berlin für Materialien und Energie, Berlin, Germany). The wavelength was $0.826 \AA$ (energy of $15 \mathrm{keV}$ ), the beam was $30 \mu \mathrm{m}$ in diameter and the scattering patterns were collected on a 2D detector (MARCCD 225, marusa, Evanston) with $73.242 \times 73.242 \mu \mathrm{m}^{2}$ pixel size and $3072 \times 3072$ pixels. The sample-detector distance was $0.310 \mathrm{~m}$, the exposure time, $10 \mathrm{~s}$ per scan point and the scan step, $100 \mu \mathrm{m}$. Measurements were calibrated using crystalline silver behenate powder. Data analyses were done with the software Fit2D [41] and Autofit, custom-made software (Max Planck Institute of Colloids and Interfaces, Potsdam, Germany). The so-called $\rho$-parameter was calculated (see Appendix A for more details). It describes the degree of alignment of the mineral particles i.e. the percentage of Mg-carb-HAP crystals presenting the same orientation in the analyzed volume $[42,43]$. Where the mineral particles were sufficiently organized $(\rho \geq 40 \%)$, the preferred orientation $\chi_{\max }$ of their c-axis was also calculated (see Appendix A for more details). The degree of organization and the orientation of the c-axis of the Mg-carb-HAP crystals respectively relate to the $\mathrm{CF}$ organization and orientation because the long axis of the CF is approximately parallel to the Mg-carb-HAP caxis $[26,28]$.

Cross-polarized light microscopy: Samples were observed by cross-polarized light microscopy (CPL, DM RXA2 Leica, Bensheim, Germany, with an air objective $2.5 x$ numerical aperture of 0.07 ), in which the polarizer and analyzer were fixed perpendicularly to each other. The microscope's goniometric stage allows rotation of the specimen with respect to the crossed polarizer and analyzer (for more details see Appendix A).

Scanning electron microscopy: A digital scanning electron microscope (SEM, DSM 962, Zeiss, Oberkochen, Germany) was used for the observations of fractured sections with the secondary electron mode in order to provide topographic contrast. The SEM was set to an accelerating voltage of $20 \mathrm{keV}$ and a working distance of $10 \mathrm{~mm}$ was used.

\section{Results.}

\section{Small- and wide-angle $X$-ray scattering}

Averaged signals from cement to pulp: Fig.2 A shows the averaged SAXS/WAXS 2D pattern of the (RL) plane profile of the mid-dentin from $\mathrm{R}=5$ to $20 \mathrm{~mm}$. It presents the characteristic (002) reflection of the Mg-carb-HAP crystals $\mathrm{c}$-axis (at $\mathrm{q}=18.4 \mathrm{~nm}^{-1}$ ), the SAXS signal of the Mg-carb-HAP particles and the signal from the spacing between dry collagen molecules (at $\mathrm{q}=5.5 \mathrm{~nm}^{-1}$ ) [44] (Fig. 2A. and Appendix B Fig. 2A). The latter presents the same azimuthal intensity distribution than the one of the Mg-carb-HAP crystals confirming that the c-axis of the Mg-carb-HAP particles is aligned along the collagen molecules axis. Therefore, we now refer to the orientation of the long axis of the MCF. On average, MCF are less organized in the (RT) plane than in the (RL) one with mean $\rho$-values of $20 \pm 8 \%$ and $49 \pm 9 \%$, respectively.

SAXS/WAXS profiles from cement to pulp: SAXS/WAXS profiles of the (RL) and (RT) planes were measured from cement $(\mathrm{R}=0 \mathrm{~mm})$ to pulp $(\mathrm{R}=25 \mathrm{~mm})$ (Fig. 2). The SAXS and WAXS profiles respectively allow the determination of the MCF organization ( $\rho$-parameter) and orientation $\left(\chi_{\max }\right.$-angle) from cement to pulp (see Appendix A for more details). The $\rho$-profile of the (RL) plane is compared with the one of the (RT) plane in Fig. $2 \mathrm{~B}$. The $\rho$-profile of the (RL) plane shows three distinct regions: 1) $\rho$ increases close to the cement, 2) it reaches a plateau in the mid-dentin and 3) it decreases close to the pulp. In the mid-dentin, the $\rho$-profile presents periodic oscillations that were further characterized by discrete Fourier transform in order to determine the period of the oscillations. The period is of $1.1 \mathrm{~mm}$ (Appendix B Fig. 3). In the (RT) plane, the $\rho$-values are quite low and spread in the mid-dentin but increase up to $60 \%$ close to the cement. Moreover, MCF orientations, $\chi_{\max }$, were determined (see Appendix A) where MCF are organized ( $\rho \geq 40 \%$ ), i.e. in the (RT) plane close to the cement and in the (RL) plane in the mid-dentin. For the (RT) plane close to the cement (from 2.6 to $3 \mathrm{~mm}$ from the cement), 
$\chi_{\max (\mathrm{RT})}$, which is the projected angle between the MCF long axis and the (T) axis is, on average, $50 \pm 6^{\circ}$ (see Appendix A). For the (RL) plane, $\chi_{\max (\mathrm{RL})}$ is the projected angle between the MCF axis and the tusk axis and varies between $-5^{\circ}$ and $5^{\circ}$ (Fig. $2 \mathrm{C}, 2 \mathrm{D}$ ). The $\chi_{\max (\mathrm{RL})}$-profile of the mid-dentin also shows periodic oscillations with a period of $1.1 \mathrm{~mm}$ (Appendix B Fig. 3).
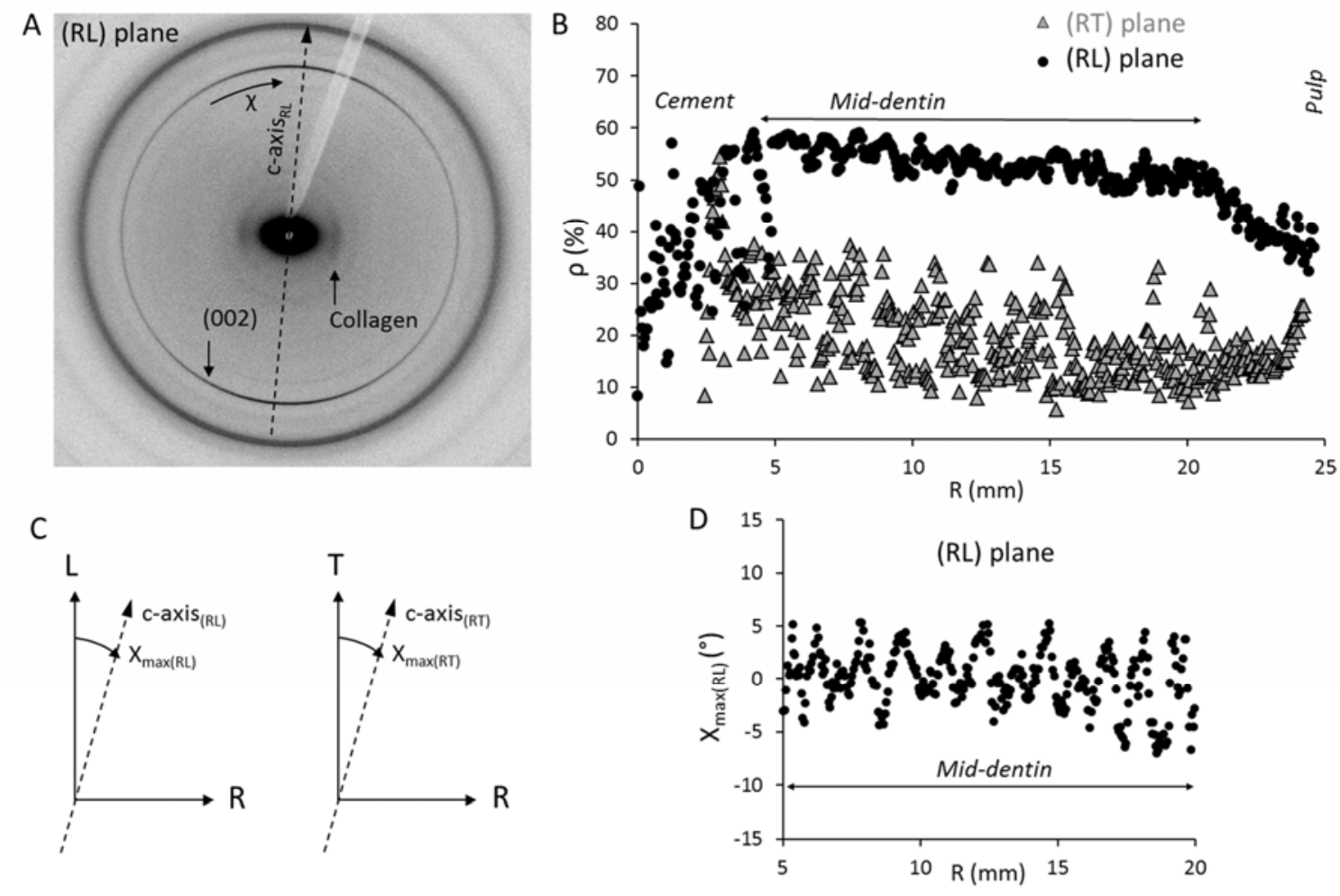

Fig. 2. Degree of organization and orientation of the MCF from cement to pulp.

A) Averaged SAXS/WAXS 2D pattern of the (RL) plane profile from $\mathrm{R}=5$ to $20 \mathrm{~mm}$ showing the typical (002) reflection of the Mg-carb-HAP particles indicative of the projection in the (RL) plane of the orientation of their c-axis $\left(\mathrm{c}\right.$-axis $\left.\mathrm{R}_{\mathrm{RL}}\right)$ and the spacing of the collagen molecules (arrows), B) $\rho$-profiles from cement to pulp of the (RL) plane (black circle) and the (RT) plane (grey triangle), C) scheme representing the angle $\chi_{\max (\mathrm{RL}) \text { and }(\mathrm{RT})}$ with respect to the (L) and (T) axis and D) $\chi_{\max (\mathrm{RL})^{-}}$ profile of the mid-dentin from 5 to $20 \mathrm{~mm}$.

\section{Macroscopic optical properties}

All mineralized thick sections and demineralized thin sections exhibit the Schreger pattern, i.e. alternating bright and dark features (Figure 3). In the (RT) plane, it consists of the checkerboard pattern composed of rhomboids of about $\sim 0.5 \times 0.5 \mathrm{~mm}^{2}$ (Fig. 3A) whereas in the (RL) plane, bright and dark bands of about $0.5 \mathrm{~mm}$ width are observed (Fig. 3B and Appendix B Fig. 4A).

The demineralized thin section of the (RT) plane (Fig. 3A right) used for CPL observations (see 3.3) better shows the clockwise Schreger lines rather than the rhomboids where bright and dark lines repeat every 1 to 1.3 $\mathrm{mm}$. The thin (RL) section used for SAXS/WAXS measurements and afterwards for CPL observations once demineralized, shows bright and dark bands that vary in width from cement $(0.5 \mathrm{~mm})$ to pulp $(0.25 \mathrm{~mm})$ (Fig. 3B) because this section was not cut exactly along the $\mathrm{R}$ axis (perpendicular to the rhomboids) otherwise the bands have a constant width from cement to pulp (Appendix B Fig. 4A).

Sections cut along the (SL) and (TL) planes also show alternating bright and dark bands that are sometimes branched. However, the contrast between dark and bright bands is much weaker than this observed for the (RT) and (RL) planes and can be better observed by transmitted light of demineralized thin sections (Appendix B Fig. $4 \mathrm{~B}$ and $\mathrm{C})$. 
Furthermore, depending on the inclination of the mineralized sections with respect to an unpolarized light source, bright and dark features turn respectively dark and bright (example is given for the (RL) plane in Fig. 3B and C). This phenomenon is also seen on demineralized thin sections (example is given for the (RL) plane Fig. 3D) where bright and dark features turn respectively dark and bright via an intermediate state, which shows bright signal at the boarder of every feature
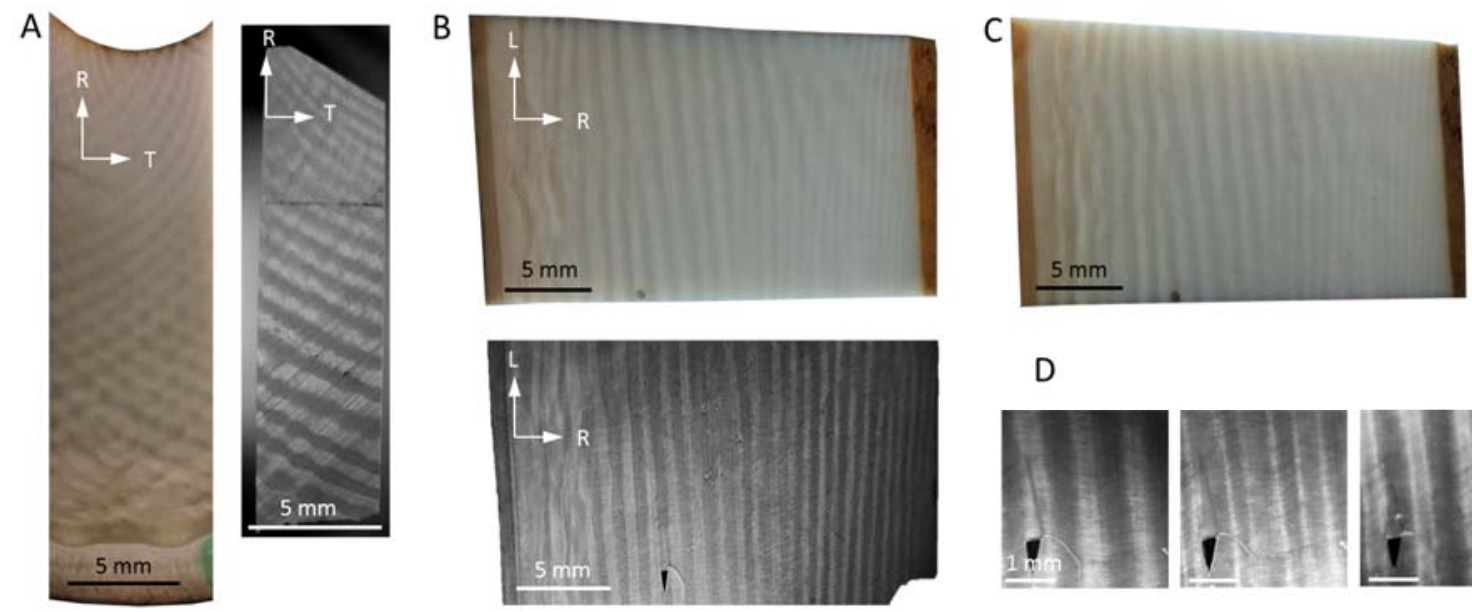

D

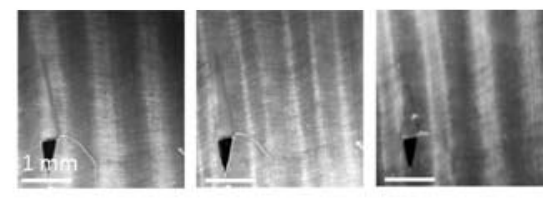

Fig.3: Schreger pattern. Mineralized thick sections observed in reflected light (colored images) and demineralized thin sections observed in transmitted light (grey scale images) of A) the (RT) plane and B-D) the (RL) plane. Effect of the inclination of the sections with respect to the light on the interchanging Schreger pattern for mineralized thick section (a black dot is indicated on a Schreger band, which is bright in top B) and dark in C)) and D) higher magnification of the demineralized thin section of B) for three different inclinations (the black triangle is a defect that helps to better appreciate the changes of the pattern).

\section{Cross-polarized light microscopy}

Demineralized samples were observed under CPL at various angles with respect to the crossed polarizer and analyzer.

The (RL) section oriented at $45^{\circ}$ to the crossed polarizer and analyzer shows strong bright thin lines $(\sim 150 \mu \mathrm{m})$ between the Schreger bands (Fig. 4A) indicating CF long axes lying in the plane of the section and oriented either at $0^{\circ}$ or $90^{\circ}$ to the tusk axis (L) (see Appendix A for more details). According to our SAXS results, we can rule out the possibility that MCF are perpendicular to the tusk axis. Therefore, $\mathrm{CF}$ at the junction between Schreger bands are mainly aligned with the tusk axis. Within the Schreger bands, a darker signal is observed indicating that $\mathrm{CF}$ are oblique or/and out of the plane of the section. When oriented at $0^{\circ}$ (Fig. 4B), the (RL) section shows a weak bright signal in the Schreger bands revealing that CF are oblique to the tusk axis and might also be out of the section plane. This relates to the darker signals observed in the middle of the bands when the sample was oriented at $45^{\circ}$. Intermediate orientations of the (RL) section $\left(+5^{\circ},-5^{\circ}\right)$ show alternating extinct dark and illuminated bright bands that are located where the Schreger bands are. Extinct and illuminated bands respectively become illuminated and extinct from one orientation (Fig. 4C) to the other (and Fig. 4D). This indicates that inclined $\mathrm{CF}$ at $+5^{\circ}$ or $-5^{\circ}$ to the tusk axis are present in the Schreger bands, and their orientation varies between bright and dark bands from $+5^{\circ}$ to $-5^{\circ}$. Moreover, a wavy pattern appears perpendicularly to the tusk axis for the section oriented at $0^{\circ}$ and $+/-5^{\circ}$.

Higher magnifications of the section oriented at $0^{\circ}$ reveal that the wavy pattern of the CF follows the tubule path (Fig. 5A). In a previous study [17], we provided evidence that tubules are helical and that the main axis of the helix is nearly perpendicular to the tusk axis (L). Once sectioned in the (RL) plane, several helical tubules are therefore seen as interrupted lines of different length having a sinusoidal trend represented by the dashed yellow line in Fig. 5A. 
Higher magnifications of the section oriented at $45^{\circ}$ shows that the longitudinal $\mathrm{CF}$ are located on the crest and the trough of the sinusoidal trend (Fig. 5B). Finally, the above CF orientations were observed from cement to pulp (Appendix B Fig. 5A).

The (SL) and (TL) planes also show a banded pattern (Fig. 4E-L). Sections oriented at $0^{\circ}$ present grey bands separated by dark lines that turns bright when samples are oriented at $45^{\circ}$ corresponding to the previously identified longitudinal $\mathrm{CF}$ at the junction between the Schreger bands. The grey bands turn interchangeably bright or dark at $+/-15^{\circ}$ revealing CF oriented at $+/-15^{\circ}$ of the tusk axis. Introducing a $\lambda$ plate at $45^{\circ}$ between the polarizer and analyzer leads to the appearance of alternating orange and blue bands that confirm the presence of tilted $\mathrm{CF}$ in each bands $\left(+/-15^{\circ}\right)$ with their orientation changing from one band to the next (Appendix B Fig. 5B). Higher magnification of the (TL) plane shows tubular cross-sections perpendicular to the main axis of the helical tubules therefore seen as ellipsoids (Fig. 5C). In the (SL) plane, tubules are cut obliquely to their main axis and due to their helical path appear either as ellipsoids or interrupted lines having a sinusoidal trend (Fig. 5D).

In all orientations of the (RT) plane, dark thin lines are observed between the features of the Schreger pattern revealing CF perpendicular to the section and corresponding to the longitudinally oriented CF (Fig. 4M-P). Here, the contrast between extinct and illuminated areas is smaller than this of the other planes and the exchange between both domains occurs at $+/-10^{\circ}$.
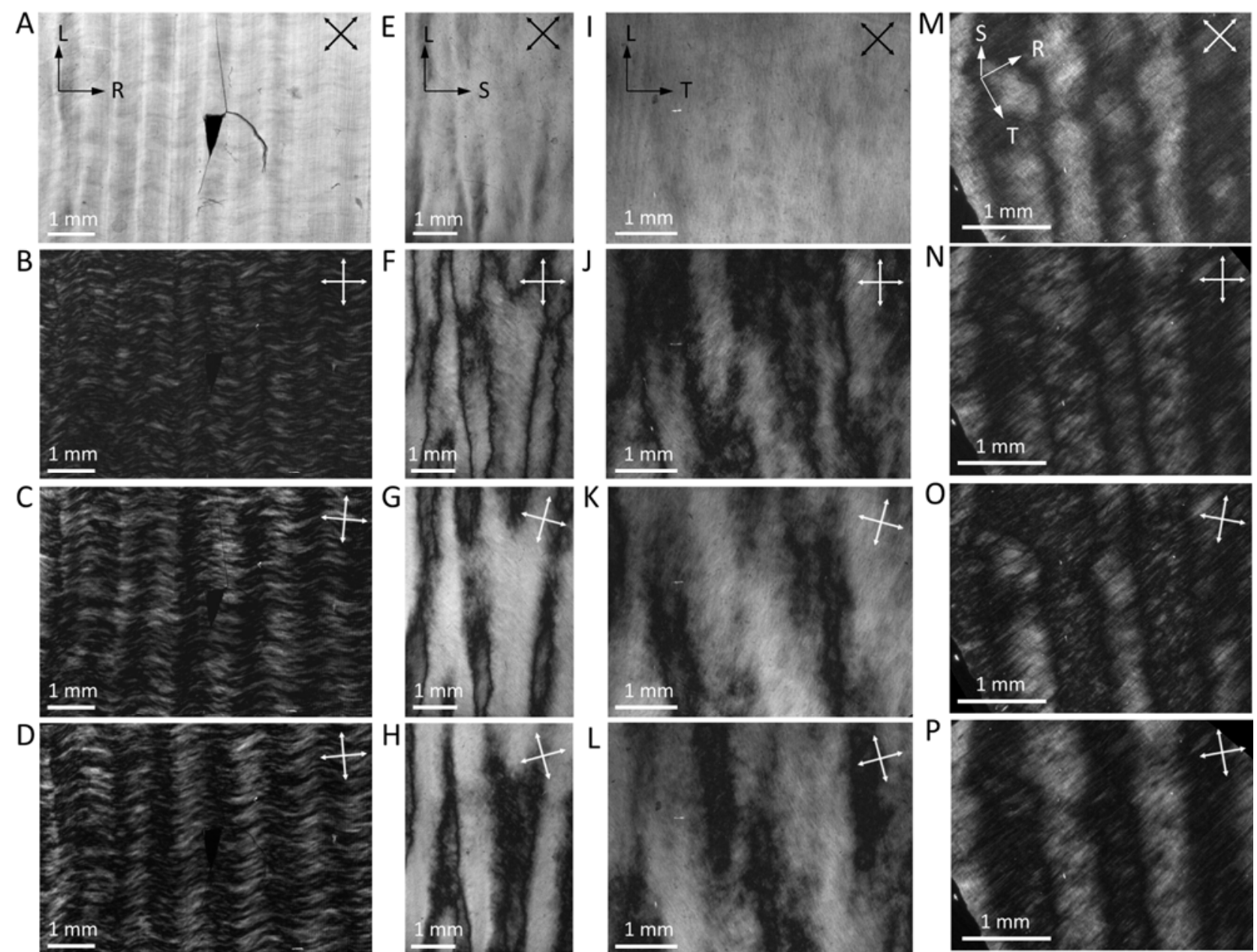

Fig.4: Orientation of the MCF in the mid-dentin. Cross-polarized light of the demineralized (RL) section oriented at A) $45^{\circ}$,

B) $\left.0^{\circ}, \mathrm{C}\right)+5^{\circ}$, D) $-5^{\circ}$, of the (SL) Schreger plane oriented at E) $\left.\left.\left.45^{\circ}, \mathrm{F}\right) 0^{\circ}, \mathrm{G}\right)+15^{\circ}, \mathrm{H}\right)-15^{\circ}$, of the (TL) tangential plane oriented at I) $\left.\left.\left.45^{\circ}, \mathrm{J}\right) 0^{\circ}, \mathrm{K}\right)+15^{\circ}, \mathrm{L}\right)-15^{\circ}$ and of the transverse plane oriented at M) $\left.\left.\left.45^{\circ}, \mathrm{N}\right) 0^{\circ}, \mathrm{O}\right)+10^{\circ}, \mathrm{P}\right)-10^{\circ}$. 

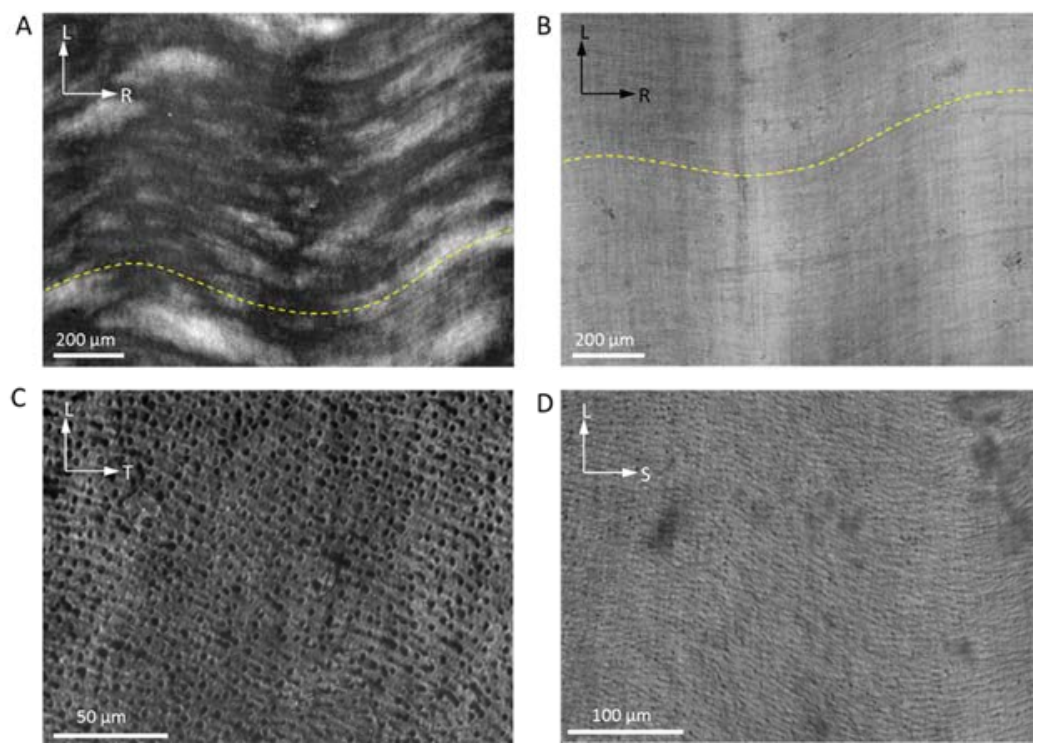

Fig.5: Relation between tubules and MCF orientation. Higher magnification images of the cross-polarized light of the (RL) longitudinal plane oriented at A) $0^{\circ}$ and B) $45^{\circ}$, C) of the (TL) plane at $45^{\circ}$ and D) of the (SL) plane at at $45^{\circ}$. The yellow dashed line represents the sinusoidal trend observed when several helical tubules are sectioned in the (RL) plane resulting in interrupted lines.

\section{Scanning electron microscopy}

Fractured elephant dentin surfaces along different planes were observed under SEM in order to reveal the MCF matrix organization (Fig. 6).

Fractures along the (RT) plane present oblique surfaces forming intercrossing ridges (Fig. 6A). Mineralized CF presenting a lamellar structure perpendicular to one tubule (yellow arrow) were identified (Fig. 6E).

Fractured sections along (RL) planes in the mid-dentin (Fig. 6B) are smoother than those of the (RT) plane, but rougher than those of the (TL) plane. The high magnification shows MCF oriented mainly parallel to the tusk axis and perpendicular to tubules (Fig. 6F). However, in some cases, a $2 \mu \mathrm{m}$ thick layer called peritubular dentine is observed around the tubules, where MCF appear to be parallel to the tubule long axis (Fig. 6F).

Fractures along (TL) planes reveal smooth surfaces indicating that MCF lie parallel to this plane (Fig. 6C). Interestingly, we note that MCF orientations in the (TL) plane vary from cement to pulp. Higher magnification of a fractured (TL) plane of the mid-dentin reveals MCF preferentially oriented within the plane (Fig. 6G) whereas close to the pulp, MCF are randomly distributed around the tubules (Appendix B Fig. 6). This is supported by SAXS measurements of (TL) planes in the mid-dentin and close to the pulp (Appendix B Fig. 6). When the impact of the fracture is directed perpendicular to the (RT) plane and close to the cement, the fracture tends to follow the Schreger rhomboids (Appendix B Fig. 7). A fracture along the (SL) plane is thus obtained where an arced pattern is observed with arcs of about $1 \mathrm{~mm}$ long (Fig. 6. D). The junction between the arcs corresponds to the corner of the rhomboids of the Schreger pattern seen in the (RT) plane (Appendix B Fig. 7). Higher magnification of this plane shows ellipsoid or elongated tubular cross sections with MCF distributed around them very similarly than in the tangential plane (Fig. $6 \mathrm{H}$ ). 
A (*)

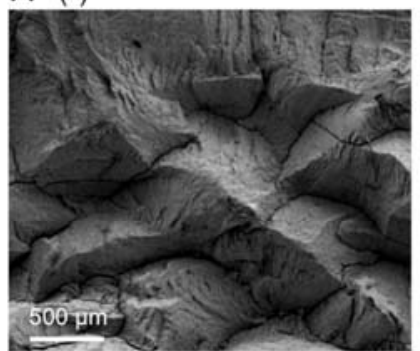

E (RT) plane

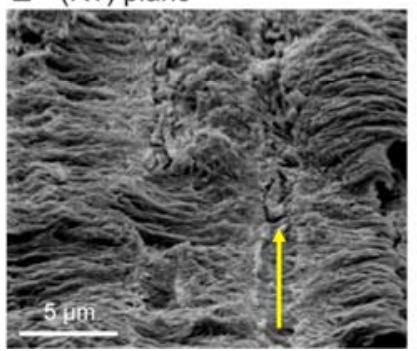

B (RL) plane

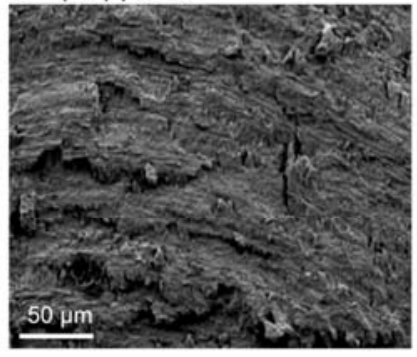

F (RL) plane

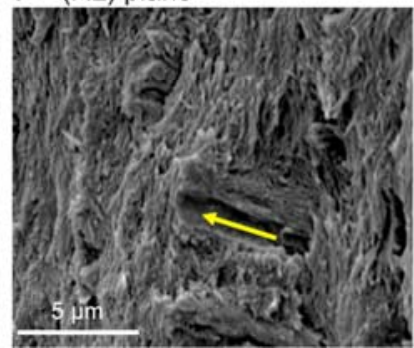

C (TL) plane

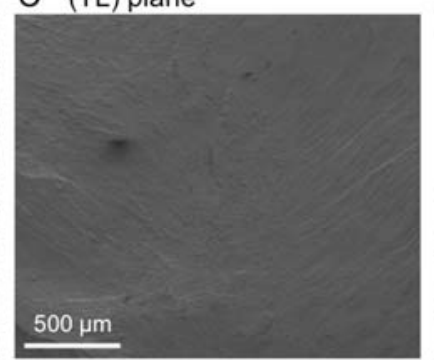

G (TL) plane

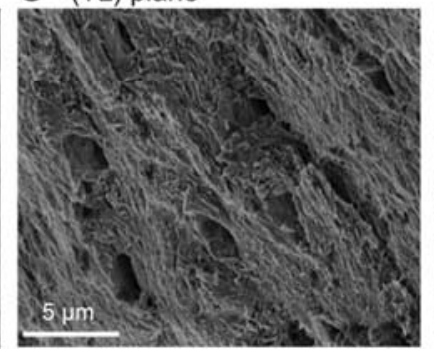

(SL) plane

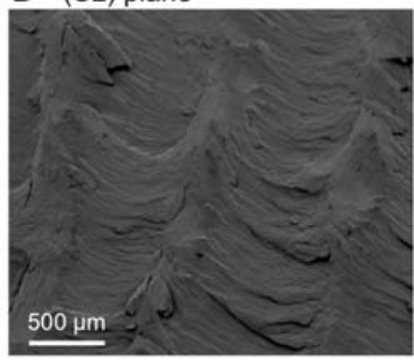

H (SL) plane

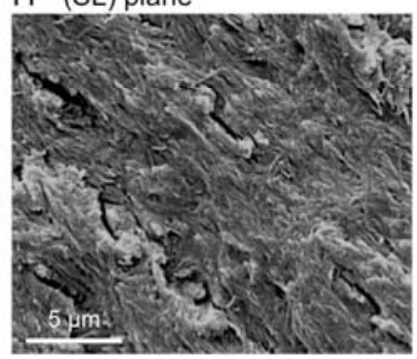

Fig.6: SEM micrographs of fractured sections of elephant dentin. The fractures are shown along: A) (*) the (RT) plane, revealing two sets of radially-distributed ridges interweaving into a network oblique to the (RT) plane, B) the (RL) plane, C) the (TL) plane, D) the (SL) plane close to the cement. Magnifications of E)- H) are high magnifications of the (RT), (RL),

(TL) and (SL) planes. Yellow arrows indicate the orientation of tubules.

\section{Discussion.}

\section{Three-dimensional MCF organization in elephant ivory from cement to pulp}

By measuring SAXS/WAXS profiles of the longitudinal planes from cement to pulp of elephant ivory, we showed that MCF are mainly oriented along the tusk axis leading to a degree of organization higher for the (RL) longitudinal plane $(\rho=50 \%)$ than for the (RT) transverse plane $(\rho=20 \%)$. This was confirmed by SEM observations and is in accordance with previous studies $[27,36]$.

Our work additionally evidences some variations of the MCF orientation from cement to pulp. Close to the cement, MCF are lying in the (RT) plane and are oriented along the cement line while close to the pulp, $\rho$ reaches similar values in both (RL) and (RT) planes ( $\sim 30 \%$ respectively), suggesting that MCF are inclined to both planes (of about $45^{\circ}$ ).

The orientation of the CF in the mid-dentin and its relation to the Schreger pattern as well as to the tubules were further characterized by CPL in four different planes. In general, all planes oriented along the tusk axis ((RL), (TL) and (SL) planes)) showed a banded pattern that corresponds to the Schreger bands. The banded pattern consists of CF inclined to the tusk axis (L) in each band and CF aligned with (L) at the junction between bands (every $\sim 0.5 \mathrm{~mm}$ ) (Fig. 7A). Moreover, juxtaposed bands present opposite orientations with respect to (L) $\left(+/-5^{\circ}\right.$ for the (RL) plane and $+/-15^{\circ}$ for the (TL) plane) (Fig. 7B). These planes are intersecting, implying that an inclination of the fibers of $+/-15^{\circ}$ in the (TL) plane results in fibers out of the (RL) plane of this same angle and vice-versa (in the (TL) plane, fibers are out of plane of $+/-5^{\circ}$ ).

The periodic oscillations of the MCF orientation (from $\sim-5^{\circ}$ to $5^{\circ}$ to the $(\mathrm{L})$ axis with $\mathrm{T} / 2=\sim 0.5 \mathrm{~mm}$ ) determined by SAXS/WAXS in the mid-dentin of the (RL) plane are in agreement with the CPL observations.

Together, these results suggest that, within two juxtaposed bands of the banded pattern and therefore of the Schreger pattern, CF oscillate back and forth from $\chi_{\max (\mathrm{RL})}$ and $\chi_{\max (\mathrm{TL})}=0^{\circ}$ (fiber (1) in Fig. $7 \mathrm{~A}$ ) to a maximum of $\chi_{\max (\mathrm{RL})}=-5^{\circ}$ and $\chi_{\max (\mathrm{TL})}=-15^{\circ}$ (fiber (2) in Fig. 7A) in one band and from $\chi_{\max (\mathrm{RL})}$ and $\chi_{\max (\mathrm{TL})}=0^{\circ}$ (fiber (3) in Fig. 7A) to $\chi_{\max (\mathrm{RL})}=5^{\circ}$ and $\chi_{\max (\mathrm{TL})}=15^{\circ}$ (fiber (4) in Fig. 7A) in the next band. 
Therefore, MCF in elephant ivory are arranged in a narrow oscillating-plywood like structure with a maximal oscillation of $15^{\circ}\left(+\right.$ or - from the tusk axis) around the (R) direction and of $5^{\circ}(+$ or - from the tusk axis) around the $(\mathrm{T})$ direction. The proposed model is also supported by our SEM observations, which showed lamellar structure of the MCF in the transverse plane.
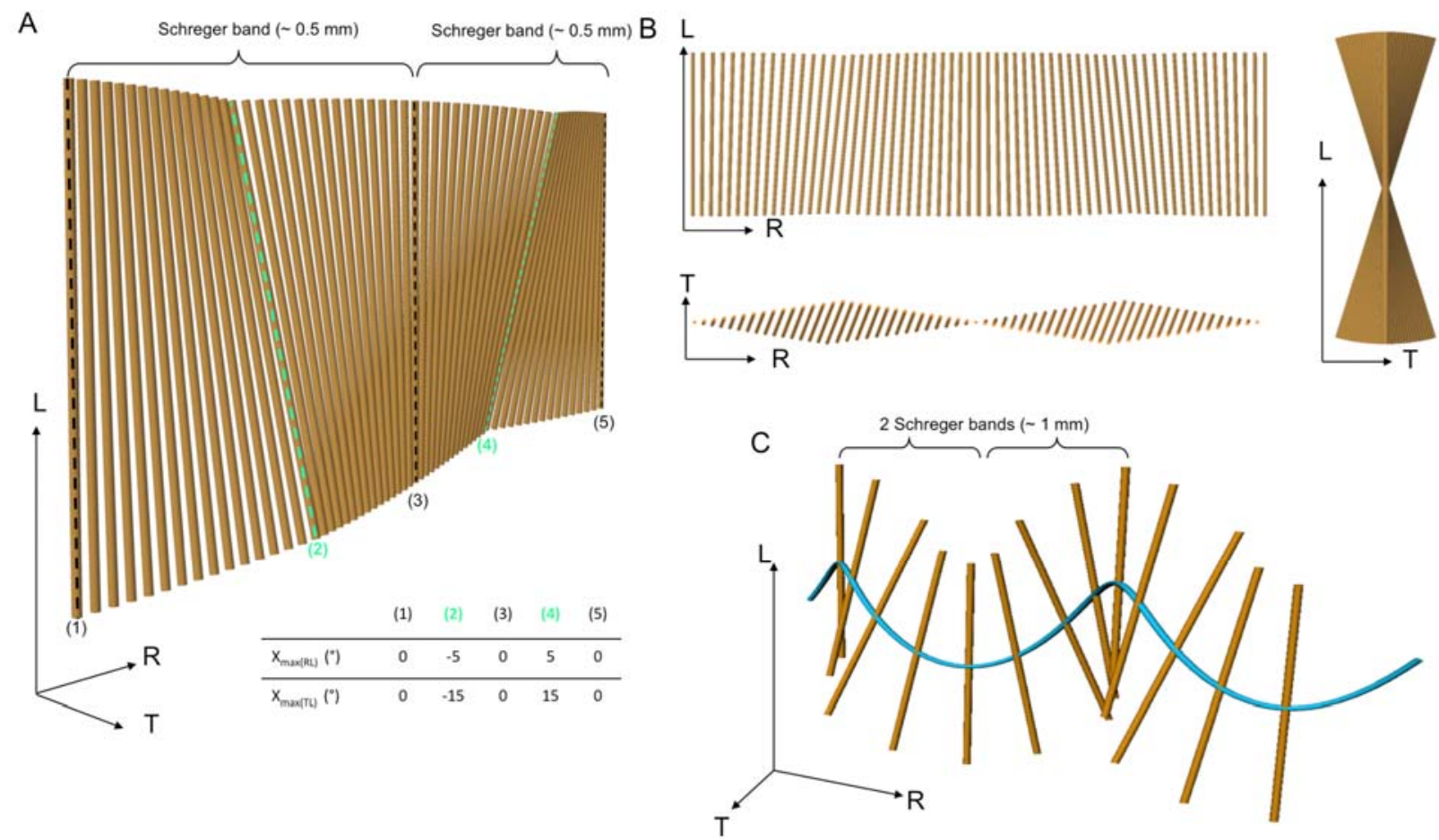

Fig.7: Model of the MCF in the mid-dentin of elephant tusks. A) 3D orientation of the MCF with the angles of the oscillating-plywood $\left(\chi_{\max (\mathrm{RL})}\right.$ and $\left.\chi_{\max (\mathrm{TL})}\right)$ indicated for 5 fibers, B) view in the three orthogonal plane (RL, TL and RT plane and C) relation of MCF orientation to one helical tubule (blue), where the position of the Schreger bands observed in the (RL) plane are indicated. The 3D software Rhinoceros (version 4 SR09) (http:// diva4rhino.com/) with the grasshopper plugin was used to generate the $3 \mathrm{D}$ representations.

Contrary to the current model based on SEM images of fractured sections of a small ivory mid-dentin volume ( $1 \mathrm{~mm}^{3}$ ) [19], our study is supported by a variety of complementary analytical techniques (SAXS/WAXS, CPL, SEM) performed on a large volume of dentin, from cement to pulp $\left(\sim 10 \mathrm{~mm}^{3}\right)$. We quantitatively measured the orientations of the MCF that was found to oscillate in a narrow range (max. $+/-15^{\circ}$ ), whereas Su and Cui [19] proposed a rotation of $90^{\circ}$. According to our analysis from cement to pulp, we determined the period of the oscillation $(\sim 1 \mathrm{~mm})$ in the mid-dentin, whereas Su and Cui [19] did not describe the complete oscillation pattern as only one rotation (over $500 \mu \mathrm{m}$ ) was reported. Therefore, our results provide evidence for an oscillatingplywood like structure of the MCF arrangement in the mid-dentin of elephant ivory.

Furthermore, the oscillating-plywood structure is likely responsible for the measured periodic oscillations of the degree of organization $\rho$ (from $\sim 50$ to $60 \%$ ), where $\rho$ is expected to be minimum when the fibers are out of plane and maximum when they are aligned within the plane. However, aligned CF to the (L) axis are observed every $\sim 0.5 \mathrm{~mm}$ and the periodicity of $\rho$ oscillations is $\sim 1.1 \mathrm{~mm}$. This apparent inconsistency can be explained by considering the relation of CF to the helical tubules. Indeed, CF aligned with the tusk axis are located perpendicularly to the crest and the trough of the helical tubules (Fig. 6 B). Tubules have a distorted helical shape with a pitch similar to the periodicity of $\rho$ oscillations $(\sim 1 \mathrm{~mm})$ [17]. Assuming that the turn of the helix occurs on the crests, MCF located on the trough are more organized than the ones on the crest (Fig. $6 \mathrm{~B}$ ) and $\rho$ is therefore minimum on the crests every $\sim 1 \mathrm{~mm}$. 
According to our results, we propose a revised model of the hierarchical scale of ivory structure in Fig. 8, where the MCF organization is reported from cement to pulp as well as its relation to the helical tubules. The schemes at the nano-scale are inspired from the data of the literature $[19,26,28,29]$.
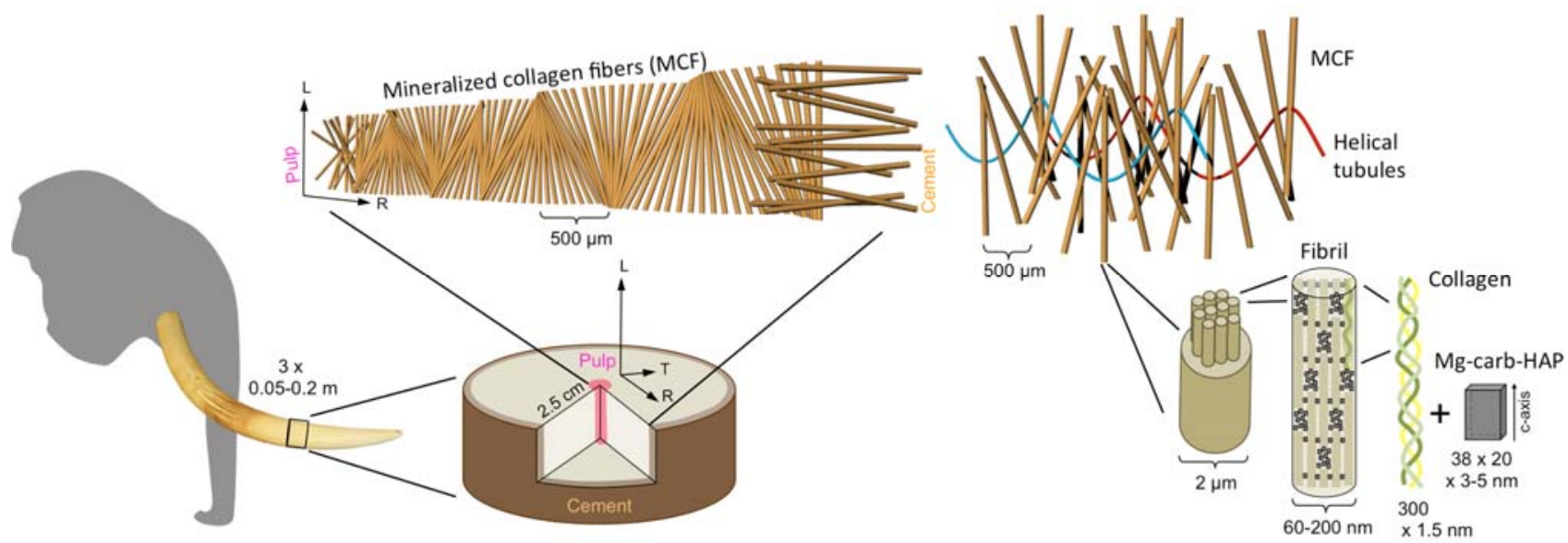

Fig. 8. Revised hierarchical model of elephant ivory structure. The data at the micro-scale are from this study and the ones at the nano-scale originate from $[19,26,28,29]$.

\section{Optical properties: origin of the unique Schreger pattern}

The origin of the Schreger pattern, which appears only on sections of Elephantoidea tusks, has been largely studied, especially in relation to the tubular network $[15,16]$. Based on this hypothesis, we recently showed that the Schreger pattern correlates to the helical tubular organization [17]. However, we could not propose a direct physical explanation to account for the interaction between the impinging light and elephant dentin microstructure, which ultimately gives rise to distinct bright and dark areas. Here, we provide new evidences showing that the CF organization primarily contributes to the emergence of the Schreger pattern.

We first showed that demineralized sections observed in transmission show the same Schreger pattern as this seen in reflection on mineralized sections (Fig. 3B), even with stronger contrast. Therefore, we suggest that the origin of the Schreger pattern mainly comes from the organization of the CF network rather than the orientation of the Mg-carb-HAP crystals. However, this does not fully rule out the fact the Mg-carb-HAP crystals may influence the Schreger pattern and this matter should be further investigated.

Second, we showed that the orientation of the CF determined by CPL strongly relate to the optical pattern in all orientations (Fig. 4). These observations on the demineralized sections in transmitted light are compatible with the optical theory of refraction from birefringent materials, a characteristic exhibited by a broad variety of collagenous tissues, which was extensively used to characterize bones and tendons under polarized light microscopy $[45,46]$.

Third, we showed that elephant ivory sections observed with different incident angles present an interchanging Schreger pattern (bright and dark features turn respectively dark and bright). This optical phenomenon is observed in both demineralized thin section (in transmission) and mineralized thick section (in reflection).

While the observations of the optical properties in transmission can be explained by the theory of refraction from birefringent materials $[45,46]$, the physical origin of the light modulation in reflection leading to the interchanging bright and dark areas depending on the incident angle of light is more complex. The properties of reflected light from a birefringent media have mostly been described by theories using Fresnel equations. Moreover, the reflected parallel-polarized component of the light is known to vanish at a critical incident angle, the Brewster angle, where the parallel-polarized component of the incident light is fully refracted through the sample, assuming a hypothetical model of a planar CF organization [47]. 
Therefore, when the incident angle of the light with the CF fibers is equal to the Brewster angle, the reflected light is minimum (as only the perpendicular-polarized component of the incident light is reflected) and thus, the surface appears dark. Because this phenomenon occurs only on the parallel-polarized component of the light, it is even stronger when the incident light is polarized. The observations of the ivory sections were mainly observed under daylight, which is in principle unpolarized. However, natural light is usually partially polarized because it interacts with materials, particles and surfaces before reaching the human eye [48]. Moreover, for birefringent materials as collagen, the value of the Brewster angle can be calculated and varies depending on the refractive index, the birefringence of the collagen fibers and their angle with the surface of the object [47]. Therefore, because bright and dark bands of the Schreger pattern have different CF orientations, they may also have different Brewster angles, for example, $B_{\text {bright }}$ and $\mathrm{B}_{\text {dark }}$ respectively. When the incident angle is equal to $\mathrm{B}_{\text {dark }}$, the dark band appears dark and the bright band, bright but when the incident angle is equal to $\mathrm{B}_{\text {bright }}$, the bright band appears dark and the dark band, bright. Therefore, the oscillations in CF orientation lead to a periodic oscillation of bright bands in reflected light and this contrast can be inverted upon tilting.

Although more precise optical measurements and simulations are required to better quantify this phenomenon, for example taking into account potential scattering effects, this simplified framework provides a conceptual basis for the emergence of the Schreger pattern.

\section{Potential implications for mechanical properties}

Previous studies showed that elephant tusks present anisotropic mechanical properties (hardness, plastic deformation, bending and tensile strength and toughness) $[27,36,37,49,50]$. Here, we attempt to relate the ivory MCF particular organization to some of these mechanical properties and further compare it to those of teeth dentin, antler and bone in terms of mechanical properties and functions.

Dentin from elephant tusks and dentin from teeth (at least human crown dentin) present MCF lying in the mineralization plane and perpendicular to tubules $[18,51,52]$. However, MCF orientation in 3D can be very different. MCF in ivory have preferential orientation along the tusk axis $[26,27,37]$ and are arranged in an oscillating plywood structure [this study], whereas MCF in the coronal dentin are mainly randomly oriented within the mineralization plane $[13,52]$. The latter is repeatedly loaded in compression, whereas elephant tusks are rather loaded in bending [37] due to their elongated shape (up to $3.5 \mathrm{~m} \mathrm{long}$ ), important weight (up to 117 $\mathrm{kg}$ ) [14] and their function of carrying loads. Therefore, MCF oriented along the tusk axis provide high resistance to bending [37] but also to tensile loads $[35,49]$ in the case of elephant tusks that is not needed in human molar crown dentin.

Improved mechanical properties in biological materials can be induced by gradients at interfaces or heterogeneities in the bulk, of their chemical composition and characteristic of their structural components [53, 54]. For example, in molar human crown dentin, MCF are progressively more organized towards the pulp [52] but also close to the enamel leading to an increased stiffness [13]. However, we showed that MCF in ivory are less organized close to the pulp and the cement than in the mid-dentin, which might be related to different growth mechanisms and/or function of teeth and tusk dentin. Furthermore, we determined that MCF close to the cement, are lying in the transverse plane and orient along the cement line. We postulate that this layer may provide cohesion of the parallel MCF of the mid-dentin in order to maintain them straight, a well-known strategy used in cell wall of plants [55].

Elephant tusks are also used as weapons like antlers, which are one of the toughest biological materials [12, 56, 57]. The toughening mechanisms in antlers have been largely studied [12, 56, 57] and similar extrinsic mechanisms were identified in the case of elephant ivory [36]. However, antlers and tusks have very different microstructure, as antlers, composed of osteons, have MCF with a single orientation between individual lamellae (aligned with the antler bone long axis) [40]. Furthermore, tusks, like teeth, do not have remodeling properties known to also increase bone toughness [10], therefore, the overall structure and the origin of the toughness in ivory may be different from the ones of antler. One recently well-studied mechanism to prevent crack propagation is the twisted plywood like structure in lamellar bones $[10,58-60]$ but also in exoskeleton of crustacean [61]. Cracks perpendicular to the MCF layers are deflected and a zigzag fracture path is observed due to the periodic oscillation of the Young's modulus [60] and the crack driving forces [59] that are imposed by the 
periodic rotation of the MCF. We hypothesize that the oscillating-plywood like structure determined in elephant ivory may also play a role in preventing crack propagation in tusks, especially in deflecting the crack path also leading to zigzag-like fractures (Fig. 6 A and Appendix B Fig 8). However, this relationship would warrant a separate study of mechanical properties of these particular samples in order to directly relate them to the structural properties.

\section{Conclusion.}

The 3D arrangement of the mineralized collagen fibers (MCF) of elephant tusk dentin was evidenced and consists of an oscillating plywood-like structure with a small angle of oscillation (maximum $15^{\circ}$ ) with respect to the tusk axis. We showed that this arrangement and the helical tubular network are intimately linked and both relate to the macroscopic Schreger pattern. However, the collagen fiber network organization seems to be mainly responsible for the optical emergence of the dark and bright pattern. We propose that the reflection of light by birefringent materials is the key to explain such phenomena, in particular the interchanging Schreger pattern. However, a quantitative modeling of this intriguing optical phenomenon requires more research, as the values of the different refractive indices of the birefringent collagen fibers depending on local fiber orientation distributions are not well known.

The oscillating-plywood structure also potentially prevents and controls crack propagation in the material. Determining the origin of the Schreger pattern and the particular fracture patterns of ivory of anthropic nature (instead of animal behavior) is essential to better interpret these features on ivory blanks or objects. Therefore, our study contributes to a better understanding of the structural origin of mechanical and optical properties in biological materials and helps apprehending how human craft has taken advantage from these properties to fulfill various purposes.

\section{Acknowledgements.}

We thank Helmholtz-Zentrum Berlin (HZB) for the allocation of synchrotron radiation beamtime at mySpot beamline at BESSY II. Beamtime has been provided through the project no. 2012_2_120106. The research leading to these results has received funding from the European Community's Seventh Framework Programme (CALIPSO FP7/2007-2013) under grant agreement n. ${ }^{\circ} 312284$. The authors are grateful to Ivo Zizak, beamline scientist of the mySpot beamline at BESSY II/HZB and Birgit Schonert for sample preparation and John Dunlop for his help with the 3D software Rhinoceros/Grasshoper at the Biomaterials department, Max-Planck Institute of Colloids and Interfaces. We are grateful to the doctoral school ED388 of the University Pierre et Marie Curie for the Ph.D grant (2011-14) and to the German Academic Exchange Service for PhD scholarship (DAAD, A1270967) for M.A, as well as to the PHC PROCOPE funding 2012-2014 (contract no. 28576YC) for the research group.

Appendix A. Detailed methods

Appendix B. Supplementary figures

\section{References.}

[1] C. Heckel, Physical characteristics of mammoth ivory and their implications for ivory work in the Upper Paleolithic, Mitteilungen der Gesellschaft für Urgeschichte 18 (2009) 71-91.

[2] C. Vercoutère, K. Müller, L. Chiotti, R. Nespoulet, A. Staude, H. Riesemeier, I. Reiche, Rectangular Beads from the Final Gravettian Level of the Abri Pataud: Raw Material Identification and its Archaeological Implications, ArcheoSciences 35 (2011) 259-271.

[3] I. Reiche, K. Müller, A. Staude, H. Riesemeier, J. Rodière, M. Allard, L. Chiotti, R. Nespoulet, C. Vercoutère, C. Schwab, J.J. Cleyet-Merle, Relation between raw material, shape, and ways of wearing of Final Gravettian ornaments from three key sites in Southern Franec (Abri Pataud, Le Blot, Les Peyrugues), L'art au quotidien - Objets ornés du Paléolothique supérieur, Les-Eyzies-de-tayac, 2016, pp. 121-122. 
[4] M. Alberic, K. Muller, L. Pichon, Q. Lernasson, B. Moignard, C. Pacheco, E. Fontan, I. Reiche, Noninvasive quantitative micro-PIXE-RBS/EBS/EBS imaging reveals the lost polychromy and gilding of the NeoAssyrian ivories from the Louvre collection, Talanta 137 (2015) 100-108.

[5] N.J. Conard, A female figurine from the basal Aurignacian of Hohle Fels Cave in southwestern Germany, Nature 459(7244) (2009) 248-252.

[6] J. Tate, I. Reiche, F. Pinzari, J. Clark, D. Caldwell, History and Surface Condition of the Lewis Chessmen in the Collection of the National Museums Scotland (Hebrides, late 12th-early 13th centuries), 35 (2011) 249-258.

[7] C.E. Heckel, S. Wolf, Ivory debitage by fracture in the Aurignacian: experimental and archaeological examples, Journal of Archaeological Science 42 (2014) 1-14.

[8] L.J.M. Daubenton, Description de l'Eléphant, in: B. GLL (Ed.), Histoire Générale et particulière, avec la description du Cabinet du Roi, Imprimerie Royale, Paris, 1764, pp. 94-142.

[9] J.L. Allen, B. Welsch, E.R. Jacobson, T.A. Turner, H. Tabeling, Medical and surgical-management of a fractured tusk in an african elephant, J. Am. Vet. Med. Assoc. 185(11) (1984) 1447-1449.

[10] W. Wagermaier, K. Klaushofer, P. Fratzl, Fragility of Bone Material Controlled by Internal Interfaces, Calcif. Tissue Int. 97(3) (2015) 201-212.

[11] P. Fratzl, S. Schreiber, A. Boyde, Characterization of bone mineral crystals in horse radius by small-angle X-ray scattering, Calcif. Tissue Int. 58(5) (1996) 341-346.

[12] M.E. Launey, P.Y. Chen, J. McKittrick, R.O. Ritchie, Mechanistic aspects of the fracture toughness of elk antler bone, Acta Biomater. 6(4) (2010) 1505-1514.

[13] A. Marten, P. Fratzl, O. Paris, P. Zaslansky, On the mineral in collagen of human crown dentine, Biomaterials 31(20) (2010) 5479-5490.

[14] E.J. Raubenheimer, M.C. Bosman, R. Vorster, C.E. Noffke, Histogenesis of the chequered pattern of ivory of the African elephant (Loxodonta Africana), Arch. Oral Biol. 43(12) (1998) 969-977.

[15] M. Locke, Structure of ivory, J. Morphol. 269(4) (2008) 423-450.

[16] A. Virag, Histogenesis of the unique morphology of proboscidean ivory, J. Morphol. 273(12) (2012) 14061423.

[17] M. Alberic, M.N. Dean, A. Gourrier, W. Wagermaier, J.W.C. Dunlop, A. Staude, P. Fratzl, I. Reiche, Relation between the Macroscopic Pattern of Elephant Ivory and Its Three-Dimensional Micro-Tubular Network, PLoS One 12(1) (2017) 22.

[18] S.J. Jones, A. Boyde, Ultrastructure of dentin and dentinogenesis, in: A. Linde (Ed.), Dentin and Dentinogenesis I, CRC Press, Boca Raton, USA, 1984, pp. 81-134.

[19] X.W. Su, F.Z. Cui, Hierarchical structure of ivory: from nanometer to centimeter, Mater. Sci. Eng. CBiomimetic Supramol. Syst. 7(1) (1999) 19-29.

[20] S. Weiner, W. Traub, H.D. Wagner, Lamellar bone: Structure-function relations, J. Struct. Biol. 126(3) (1999) 241-255.

[21] M.M. Giraud-Guille, twisted plywood architecture of collagen fibrils in human compact-bone osteons, Calcif. Tissue Int. 42(3) (1988) 167-180.

[22] P. Varga, A. Pacureanu, M. Langer, H. Suhonen, B. Hesse, Q. Grimal, P. Cloetens, K. Raum, F. Peyrin, Investigation of the three-dimensional orientation of mineralized collagen fibrils in human lamellar bone using synchrotron X-ray phase nano-tomography, Acta Biomater. 9(9) (2013) 8118-8127.

[23] W. Geghardt, Über funktionell wichtige Anordnungsweisen der feineren und gröberen Bauelemente des Wirbeltierknochens, Archiv für Entwicklungsmechanik der Organismen 20 (1905) 187-322.

[24] W. Wagermaier, H.S. Gupta, A. Gourrier, M. Burghammer, P. Roschger, P. Fratzl, Spiral twisting of fiber orientation inside bone lamellae, Biointerphases 1(1) (2006) 1-5.

[25] J. Mitchell, A.H. van Heteren, A literature review of the spatial organization of lamellar bone, C. R. Palevol 15(1-2) (2016) 23-31.

[26] F.Y. Cui, H.B. Wen, H.B. Zhang, C.L. Ma, H.D. Li, Nanophase hydroxyapatite-like crystallites in natural ivory, J. Mater. Sci. Lett. 13 (1994) 1042-1044.

[27] F.Z. Cui, H.B. Wen, H.B. Zhang, H.D. Li, D.C. Liu, Anisotropic indentation morphology and hardness of natural ivory, Mater. Sci. Eng. C-Biomimetic Mater. Sens. Syst. 2(1-2) (1994) 87-91. 
[28] X.W. Su, F.Z. Cui, Direct observations on apatite crystals in ivory, J. Mater. Sci. Lett. 16(14) (1997) 11981200.

[29] V. Jantou-Morris, M.A. Horton, D.W. McComb, The nano-morphological relationships between apatite crystals and collagen fibrils in ivory dentine, Biomaterials 31(19) (2010) 5275-5286.

[30] J.D. Currey, Mechanical-properties of bone tissues with greatly differing functions, J. Biomech. 12(4) (1979) 313-319.

[31] S. Weiner, H.D. Wagner, The material bone: Structure mechanical function relations, Annu. Rev. Mater. Sci. 28 (1998) 271-298.

[32] P. Fratzl, H.S. Gupta, E.P. Paschalis, P. Roschger, Structure and mechanical quality of the collagen-mineral nano-composite in bone, J. Mater. Chem. 14(14) (2004) 2115-2123.

[33] J.W.C. Dunlop, P. Fratzl, Biological Composites, in: D.R. Clarke, M. Ruhle, F. Zok (Eds.), Annual Review of Materials Research, Vol 40, Annual Reviews, Palo Alto, 2010, pp. 1-24.

[34] M.A. Meyers, P.Y. Chen, A.Y.M. Lin, Y. Seki, Biological materials: Structure and mechanical properties, Progress in Materials Science 53(1) (2008) 1-206.

[35] A. Rajaram, Tensile properties and fracture of ivory, J. Mater. Sci. Lett. 5(10) (1986) 1077-1080.

[36] R.K. Nalla, J.H. Kinney, R.O. Ritchie, Effect of orientation on the in vitro fracture toughness of dentin: the role of toughening mechanisms, Biomaterials 24(22) (2003) 3955-3968.

[37] G. Nothnagel, S.D. Le Roux, W. Grotepass, Correlation Between Texture of Hydroxyapatite and Mechanical Anisotropy in Loxodonta Africana Ivory, Textures and Microstructures 26 (1996) 579-583.

[38] M.G. Ascenzi, A. Ascenzi, A. Benvenuti, M. Burghammer, S. Panzavolta, A. Bigi, Structural differences between "dark" and "bright" isolated human osteonic lamellae, J. Struct. Biol. 141(1) (2003) 22-33.

[39] A. Gourrier, C.H. Li, S. Siegel, O. Paris, P. Roschger, K. Klaushofer, P. Fratzl, Scanning small-angle X-ray scattering analysis of the size and organization of the mineral nanoparticles in fluorotic bone using a stack of cards model, J. Appl. Crystallogr. 43 (2010) 1385-1392.

[40] S. Krauss, W. Wagermaier, J.A. Estevez, J.D. Currey, P. Fratzl, Tubular frameworks guiding orderly bone formation in the antler of the red deer (Cervus elaphus), J. Struct. Biol. 175(3) (2011) 457-464.

[41] A.P. Hammersley, S.O. Svensson, M. Hanfland, A.N. Fitch, D. Hausermann, Two-dimensional detector software: From real detector to idealised image or two-theta scan, High Pressure Res. 14(4-6) (1996) 235-248.

[42] P. Fratzl, N. Fratzlzelman, K. Klaushofer, G. Vogl, K. Koller, Nucleation and growth of mineral crystals in bone studied by small-angle x-ray-scattering, Calcif. Tissue Int. 48(6) (1991) 407-413.

[43] P. Fratzl, M. Groschner, G. Vogl, H. Plenk, J. Eschberger, N. Fratzlzelman, K. Koller, K. Klaushofer, Mineral crystals in calcified tissues - a comparative-study by SAXS, J. Bone Miner. Res. 7(3) (1992) 329-334.

[44] P.M. Cowan, S. McGavin, A.C.T. North, The polypeptide chain configuration of collagen, Nature 176 (1955) 10621064.

[45] B.C. Vidal, Form birefringence as applied to biopolymer and inorganic material supraorganization, Biotech. Histochem. 85(6) (2010) 365-378.

[46] M.M. Giraud-Guille, L. Besseau, Banded patterns in liquid crystalline phases of type I collagen: Relationship with crimp morphology in connective tissue architecture, Connect. Tissue Res. 37(3-4) (1998) 183193.

[47] M.C. Simon, K.V. Gottschalk, About the Brewster angle and the electric polarization in birefringent media, Pure and Applied Optics: Journal of the European Optical Society Part A 4 (1995) 27-38.

[48] T.W. Cronin, J. Marshall, Patterns and properties of polarized light in air and water, Philos. Trans. R. Soc. B-Biol. Sci. 366(1565) (2011) 619-626.

[49] W. Bonfield, C.H. Li, Deformation and fracture of ivory, J. Appl. Phys. 36(10) (1965) 3181-\&.

[50] F. Vollrath, M. Ruixin, D. U. Shah, Ivory as an important Bio-composite, Curator: The Museum Journal 61(1) (2018) 95-109.

[51] N.W. Johnson, D.F.G. Poole, Orientation of collagen fibres in rat dentine, Nature 213(5077) (1967) 695-\&.

[52] J.H. Kinney, J.A. Pople, G.W. Marshall, S.J. Marshall, Collagen orientation and crystallite size in human dentin: A small angle X-ray scattering study, Calcif. Tissue Int. 69(1) (2001) 31-37.

[53] W. Tesch, N. Eidelman, P. Roschger, F. Goldenberg, K. Klaushofer, P. Fratzl, Graded microstructure and mechanical properties of human crown dentin, Calcif. Tissue Int. 69(3) (2001) 147-157. 
[54] Z.Q. Liu, Y.K. Zhu, D. Jiao, Z.Y. Weng, Z.F. Zhang, R.O. Ritchie, Enhanced protective role in materials with gradient structural orientations: Lessons from Nature, Acta Biomater. 44 (2016) 31-40.

[55] D. Fengel, G. Wegener, Wood: chemistry, ultrastructure, reactions, De Gruyter 1983.

[56] S. Krauss, P. Fratzl, J. Seto, J.D. Currey, J.A. Estevez, S.S. Funari, H.S. Gupta, Inhomogeneous fibril stretching in antler starts after macroscopic yielding: Indication for a nanoscale toughening mechanism, Bone 44(6) (2009) 1105-1110.

[57] H.S. Gupta, S. Krauss, M. Kerschnitzki, A. Karunaratne, J.W.C. Dunlop, A.H. Barber, P. Boesecke, S.S. Funari, P. Fratzl, Intrafibrillar plasticity through mineral/collagen sliding is the dominant mechanism for the extreme toughness of antler bone, J. Mech. Behav. Biomed. Mater. 28 (2013) 366-382.

[58] H. Peterlik, P. Roschger, K. Klaushofer, P. Fratzl, From brittle to ductile fracture of bone, Nat. Mater. 5(1) (2006) 52-55.

[59] F.D. Fischer, O. Kolednik, J. Predan, H. Razi, P. Fratzl, Crack driving force in twisted plywood structures, Acta Biomater. 55 (2017) 349-359.

[60] H.S. Gupta, U. Stachewicz, W. Wagermaier, P. Roschger, H.D. Wagner, P. Fratzl, Mechanical modulation at the lamellar level in osteonal bone, Journal of Materials Research 21(8) (2006) 1913-1921.

[61] J.C. Weaver, G.W. Milliron, A. Miserez, K. Evans-Lutterodt, S. Herrera, I. Gallana, W.J. Mershon, B. Swanson, P. Zavattieri, E. DiMasi, D. Kisailus, The Stomatopod Dactyl Club: A Formidable Damage-Tolerant Biological Hammer, Science 336(6086) (2012) 1275-1280. 


\section{Appendix A - Detailed methods}

\section{Small- and wide- angle $X$-ray scattering}

Experimental set up: small- and wide- angle X-ray scattering (SAXS/WAXS) experiments were performed at the mySpot beamline at the BESSY II synchrotron radiation facility (HZB, Helmholtz-Zentrum Berlin für Materialien und Energie, Berlin, Germany). The wavelength was $0.826 \AA$ (energy of $15 \mathrm{kev}$ ), the beam was 30 $\mu \mathrm{m}$ large and the scattering patterns were collected on a 2D detector (MARCCD 225, marusa, Evanston) with $73.242 \times 73.242 \mu \mathrm{m}^{2}$ pixel size and $3072 \times 3072$ pixels. The sample-detector distance was $0.310 \mathrm{~m}$. The exposure time was $10 \mathrm{~s}$ per scan point. The scan step was $100 \mu \mathrm{m}$. Measurements were calibrated using crystalline silver behenate powder.

Data analysis: the SAXS signal arises from electron density differences between the HAP nano platelets and the organic collagen matrix. The shape of the two dimensional (2D) SAXS signal provides information on the average degree of alignment of the mineral platelets within the irradiated sample volume. Thus, an anisotropic 2D SAXS signal indicates a high organization of the mineral platelets in one specific orientation (Figure $1 \mathrm{~A}$ ), whereas an isotropic 2D SAXS signal is due to randomly oriented HAP particles (Figure $1 \mathrm{~B}$ ). However, if the mineral particles (with their long dimension) are not parallel to the beam, an isotropic SAXS signal can also result from out-of plane particle orientation $[1,2]$.
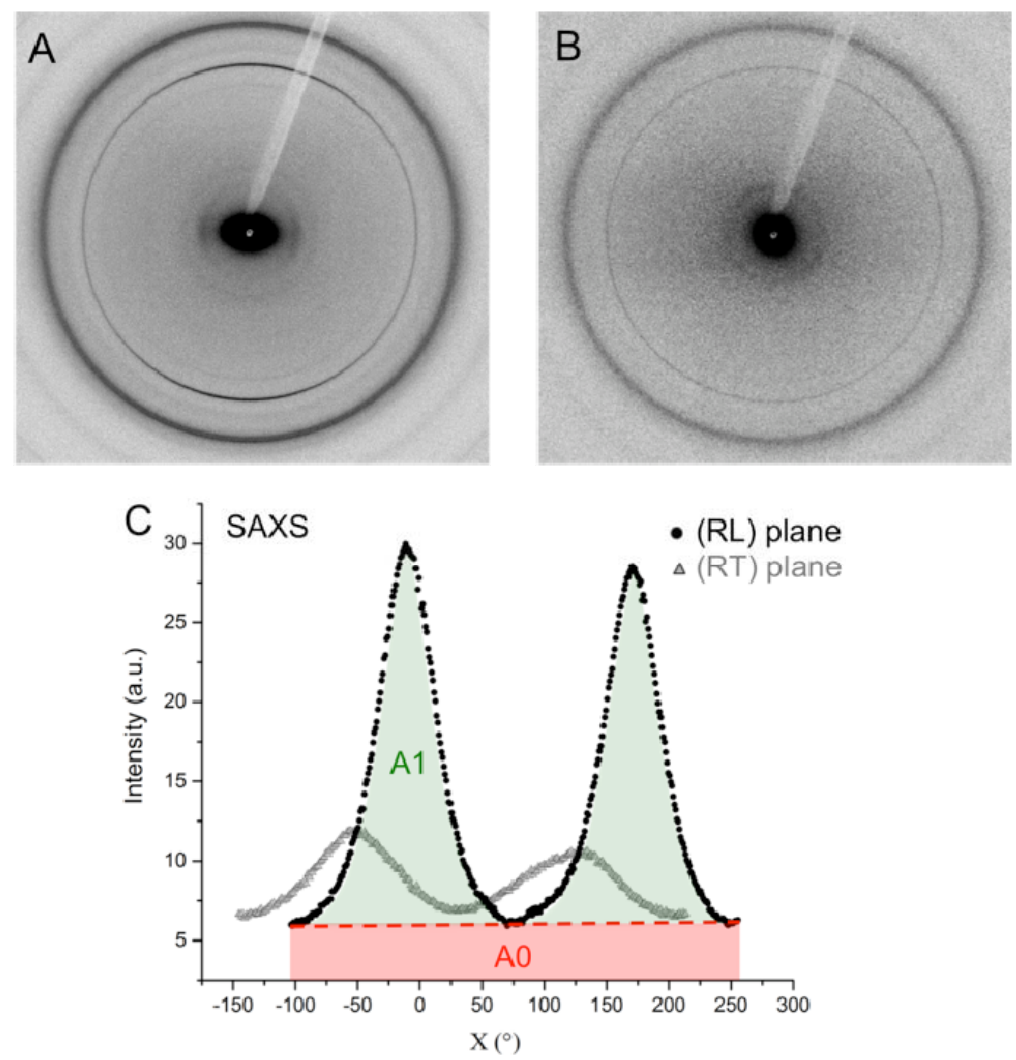

Figure 1. A) Averaged SAXS/WAXS 2D pattern of the (RL) plane profile from $\mathrm{R}=5$ to $20 \mathrm{~mm}$, B) averaged SAXS/WAXS 2D pattern of the (RT) plane from $R=0$ to $3 \mathrm{~mm}$ and $\mathrm{C}$ ) radial integration of the SAXS signals of the (RL) and (RT) sections showing the area $\mathrm{A} 1$ and $\mathrm{A} 0$ for the calculation of the $\rho$-parameter for the (RL) plane.

A more quantitative analysis can be done by calculating the $\rho$-parameter $[3,4]$. The $\rho$-parameter describes the degree of alignment of the mineral particles i.e. the percentage of HAP crystals presenting the same orientation 
in the analyzed volume. It is calculated from the radial integration of the SAXS signals (Fig. 1C) by $\rho=$ $\mathrm{A} 1 /(\mathrm{A} 1+\mathrm{A} 0)$ where $\mathrm{A} 1$ represents the percentage of organized HAP particles having a preferred orientation and A0 the percentage of randomly oriented HAP particles.

The $\rho$-parameter does not, however, provide any information concerning out of plane orientations. Therefore, a $\rho$-parameter of 0 means that HAP minerals are randomly oriented or that they are oriented but with their axis along the long dimension perpendicular to the beam. A $\rho$-parameter equal to $100 \%$ means that HAP particles present a preferred orientation.

Finally, where the mineral particles are sufficiently organized ( $\rho \geq 40 \%)$, it is possible to assess the preferred orientation of their c-axis by the previous radial integration of the SAXS signal (Figure 1 C) or of the (002) reflection of the HAP crystals seen in the 2D WAXS pattern. The intensity distribution of this reflection shows the probability of HAP c-axes to be oriented in a given direction $\chi_{\max }$ (maximum of the intensity of the $\chi$ distribution), which is the c-axes projection in the sample plane with respect to the vertical of the samples. In the case of the (RL) section, the sample was aligned with the (L) axis perpendicular to the beam and in the case of the (RT) section, the sample was aligned with the (T) axis perpendicular to the beam. Therefore, $\chi_{\max (\mathrm{RL})}$ is the projected angle between the MCF axis and the tusk axis and $\chi_{\max (\mathrm{RT})}$ is the projected angle between the MCF long axis and the (T) axis.

The $\rho$-parameter and $\chi_{\max }$-angle were calculated after having respectively integrated the 2D SAXS and WAXS signals as a function of the azimuthal angle using the software Fit2D (Hammersley et al., 1996) and Autofit, custom-made software (Max Planck Institute of Colloids and Interfaces, Potsdam, Germany).

For the (RT) plane, $\chi_{\max (\mathrm{RT})}$ values were extracted from 2.6 to $3 \mathrm{~mm}$ from the cement. The reported are reported in the table below. Values from 2.6 to $3 \mathrm{~mm}$ are missing because the section broke close to the cement due to low thickness.

\begin{tabular}{ccc}
$\begin{array}{c}\text { Position from cement } \\
(\mathrm{R} \text { in mm) }\end{array}$ & $\rho$-parameter (\%) & $\begin{array}{c}\chi \max (\mathrm{RT}) \\
\left({ }^{\circ}\right)\end{array}$ \\
\hline 2.6 & 42 & 56 \\
2.65 & 44 & 53 \\
2.7 & 46 & 46 \\
2.75 & 48 & 54 \\
2.8 & 51 & 46 \\
2.85 & 51 & 56 \\
2.9 & 54 & 52 \\
2.95 & 49 & 44 \\
3 & 42 & 40 \\
\hline & Average & 50 \\
& SDV & 6 \\
\hline
\end{tabular}

\section{Cross-polarized light and scanning electron microscopy}

Samples were observed by cross-polarized light microscopy (CPL, DM RXA2 Leica, Bensheim, Germany, with air objective $2.5 \mathrm{x}$ numerical aperture of 0.07 ) in which the polarizer and analyzer were fixed perpendicularly to each other (cross-polarized light). The microscope's goniometric stage allows rotation of the specimen with respect to the crossed polarizers. The intensity of the transmitted light depends on the collagen content, its degree of alignment, on the mineral fraction and on the orientation of the section. Therefore, we demineralized the sections (see 2.2 for details). As seen by the WAXS pattern of the (RL) sections before and after removal of 
the mineral part, the demineralization process was successful. The mineralized section shows the typical HAP signals with the (002), (211), (112) and (300) reflections whereas the demineralized section does not show them.

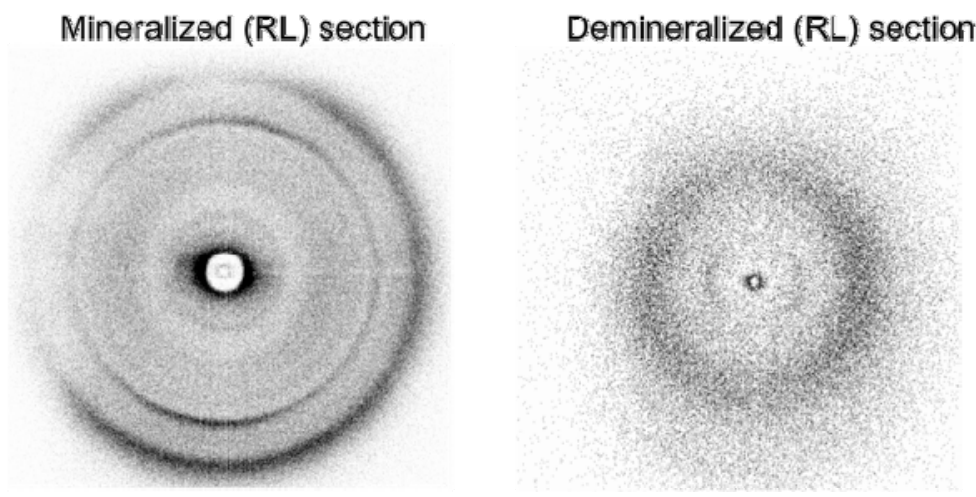

The demineralized sections with controlled thicknesses $(\sim 70 \mu \mathrm{m})$ were measured at various angles from the crossed polarizers in order to determine the collagen fibers (CF) orientations by distinguishing extinction and illumination positions. Due to the interaction between light and the tissue, the brightest areas will be observed for $\mathrm{CF}$ lying in the observation plane (i.e. normal to the light propagation) and oblique $\left(+\right.$ or $\left.-45^{\circ}\right)$ to the analyzer and polarizer, while darker regions will correspond to $\mathrm{CF}$ oriented perpendicularly to this direction or within the plane but orientated parallel to the direction of either the analyzer or the polarizer. In order to determine if $\mathrm{CF}$ in bright areas are oriented at + or $-45^{\circ}$ to the crossed polarizer and analyzer, a quartz first-order retardation $\lambda$ plate was at $45^{\circ}$ between the polarizer and analyzer. Indeed, the $\lambda$ plate allows evidencing $\mathrm{CF}$ oriented parallel to the slow axis of the $\lambda$ plate (blue domains) and CF perpendicular to it (orange domains).

A digital scanning electron microscope (SEM, DSM 962, Zeiss, Oberkochen, Germany) was used for the observations of fractured sections with the secondary electron mode in order to provide topographic contrast. The SEM was set to an accelerating voltage of $20 \mathrm{keV}$ and a working distance of $10 \mathrm{~mm}$ was used. 


\section{Appendix B - Supplementary figures}
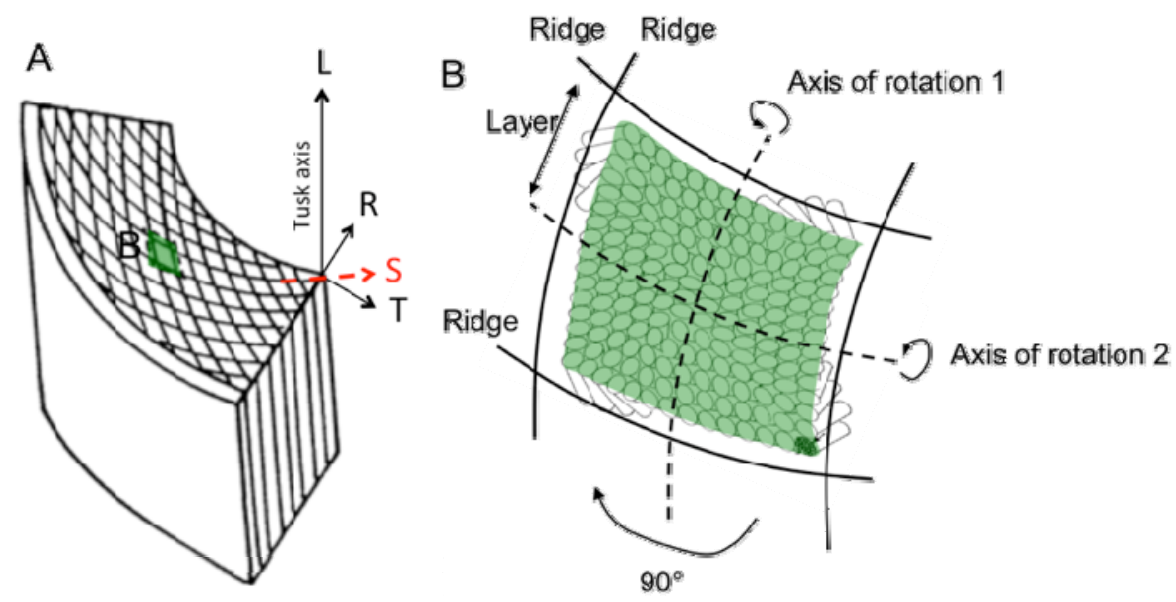

Supplementary Fig. 1. 3D arrangement of the mineralized collagen fibers in elephant ivory proposed by [5]. A) Scheme of a section of ivory with the reference system indicated, the transverse (RT) plane shows the intercrossing ridges of the Schreger pattern and B) rotated plywood like structure showing the two orthogonal axes of rotation following the Schreger lines. Mineralized CF continuously rotate of $90^{\circ}$ from one layer to the other and are mainly oblique to the transverse plane apart on top and bottom of the ridges were they are perpendicular to it and therefore aligned to the tusk axis.

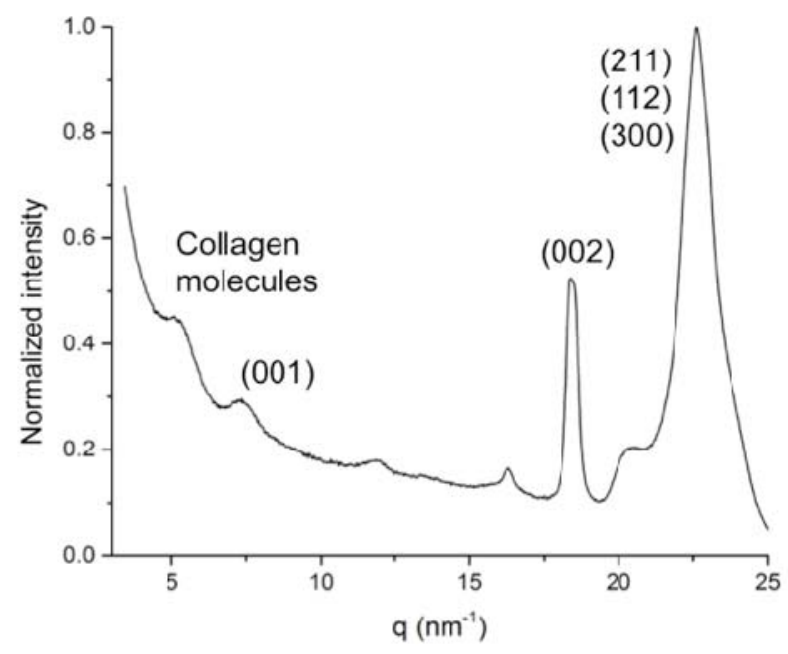

Supplementary Fig. 2. Azimuthal integration of the averaged SAXS/WAXS 2D pattern of the (RL) plane profile from cement to pulp showing the peak corresponding to the spacing between collagen molecules $\left(5.5 \mathrm{~nm}^{-1}\right)$ and the different reflections of the HAP crystals with the characteristic (002) reflection at $\mathrm{q}=18.4 \mathrm{~nm}^{-1}$. 

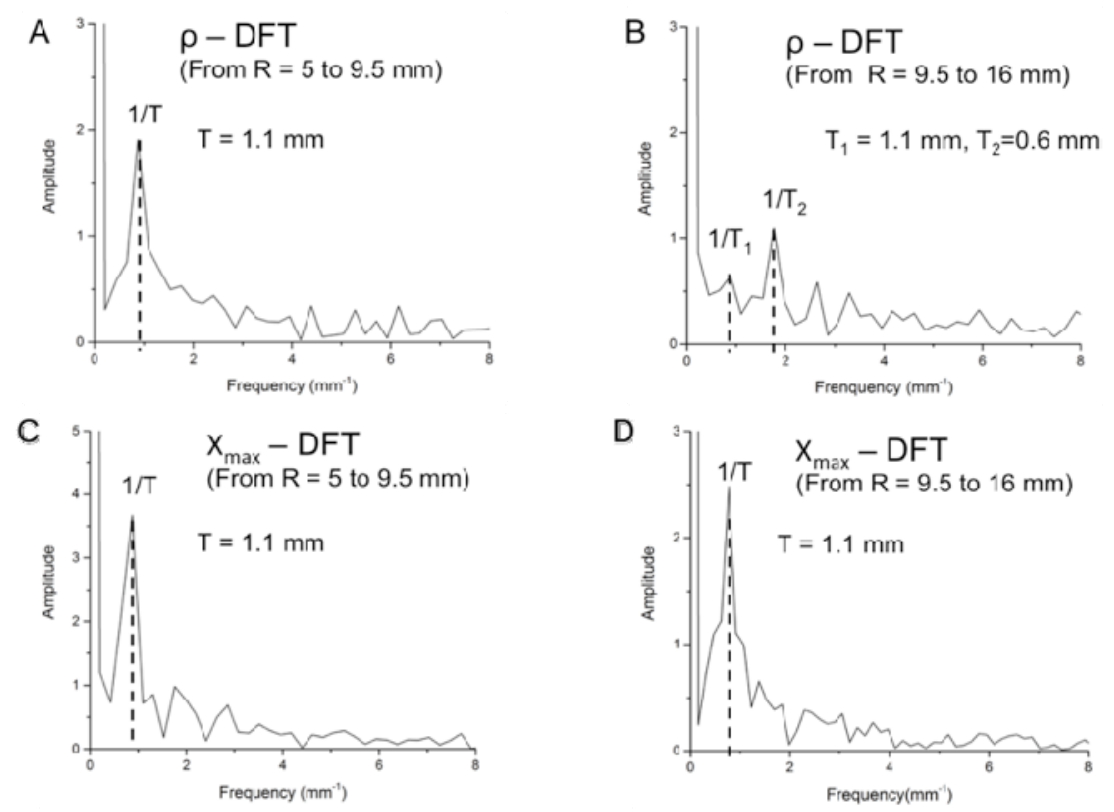

Supplementary Fig. 3. Discrete Fourier Transform (DFT) of the periodic oscillations of the $\rho$ - and $\chi_{\max }$ profiles in the middentin of the (RL) plane. A) from $R=5$ to $9.5 \mathrm{~mm}$ of the $\rho$-profile, $B$ ) from $R=9.5$ to $16 \mathrm{~mm}$ of the $\rho$-profile, $C$ ) from $R=5$ to $9.5 \mathrm{~mm}$ of the $\chi_{\max }$-profile and $\left.\mathrm{D}\right)$ from $\mathrm{R}=9.5$ to $16 \mathrm{~mm}$ of the $\chi_{\max }$-profile.
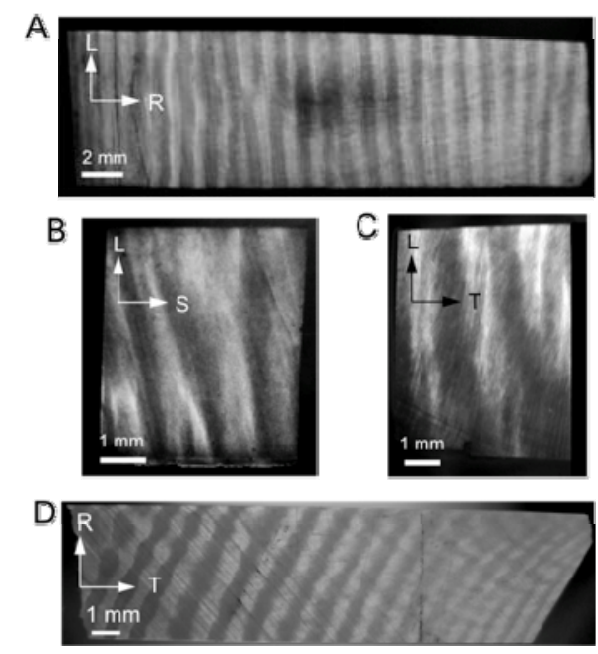

Supplementary Fig. 4. Thin demineralized sections observed under transmitted light and used for cross-polarised microscopy measurements. A) (RL) section cut perpendicular to the rhomboids from cement to pulp, B) (SL) section, C) (TL) section and D) (RT) section. 

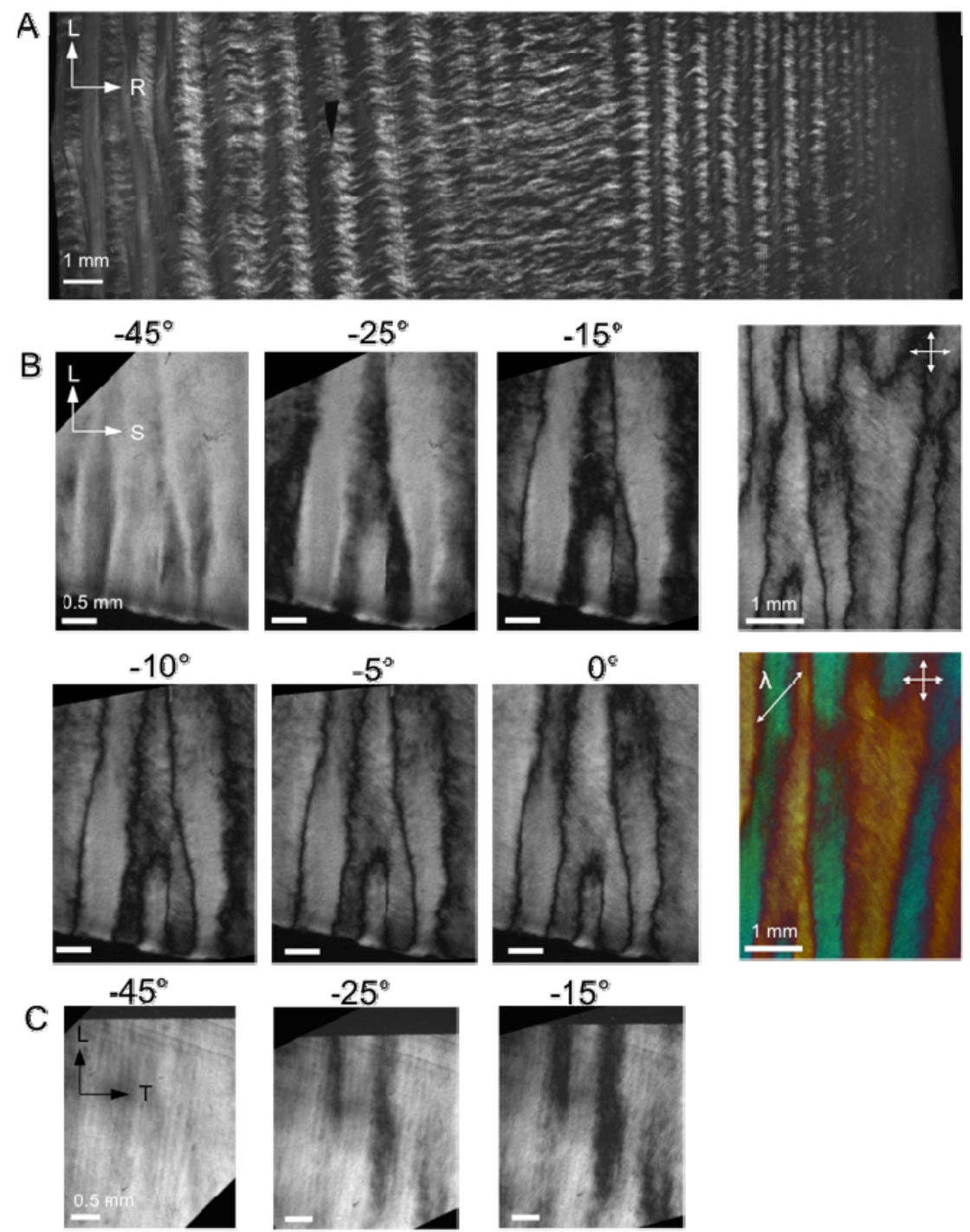

$-15^{\circ}$

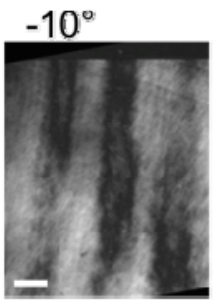

$-5^{\circ}$
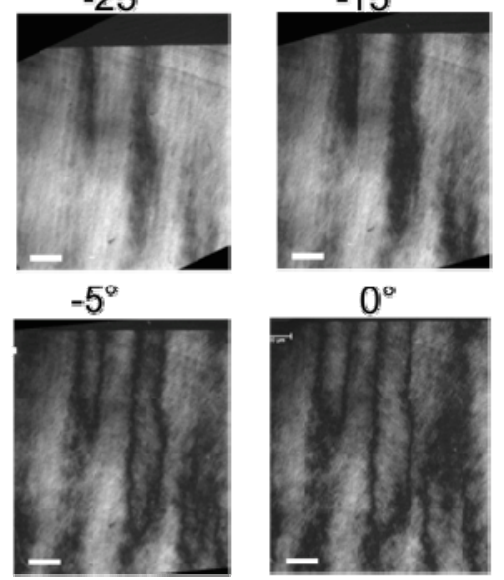

Supplementary Fig. 5. Cross-polarized micrographs of A) the (RL) plane (section used for SAXS/WAXS measurements)

from cement to pulp oriented at $5^{\circ}$ to the crossed polarizer and analyzer, B) the (SL) section oriented at different orientations and with the additional presence of the $\lambda$ plate for the orientation at $0^{\circ}$ and $\mathrm{C}$ ) the (TL) plane at different orientations. 

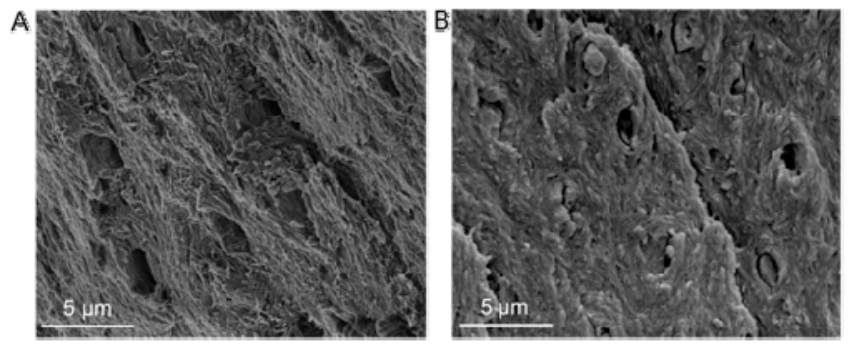

C

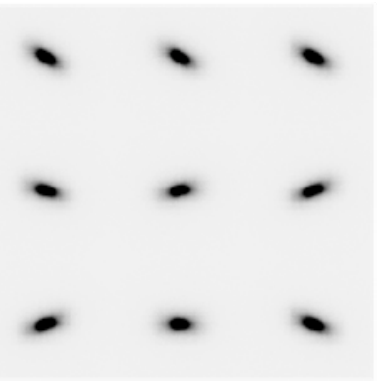

D

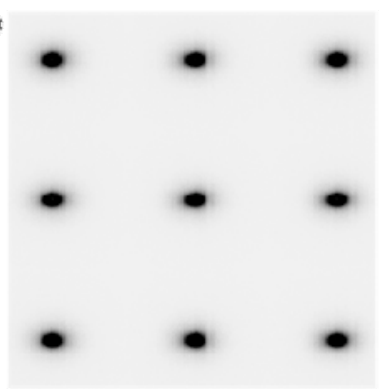

Supplementary Fig. 6. Variation of the MCF orientation in the (TL) plane from cement to pulp. A) SEM image of a fractured section in the mid-dentin which shows MCF aligned in the plane and B) SEM image of a fracture section close to the pulp with MCF distributed around the tubules and having different orientations. C) Anisotropic SAXS signals of a (TL) section in the mid-dentin indicating preferentially aligned MCF and D) Isotropic SAXS signals of a (TL) section close to the pulp revealing less organized MCF than in the mid-dentin.

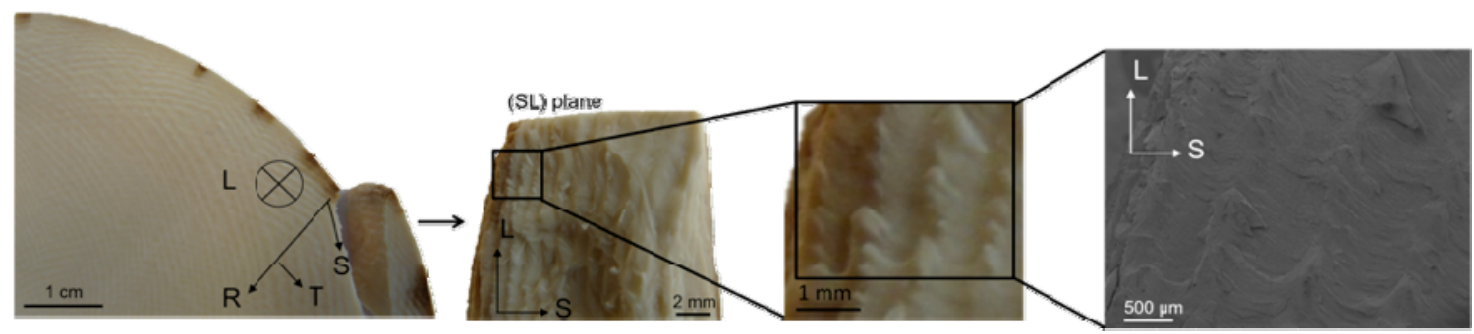

Supplementary Fig. 7. Fractured section along the (SL) plane. 


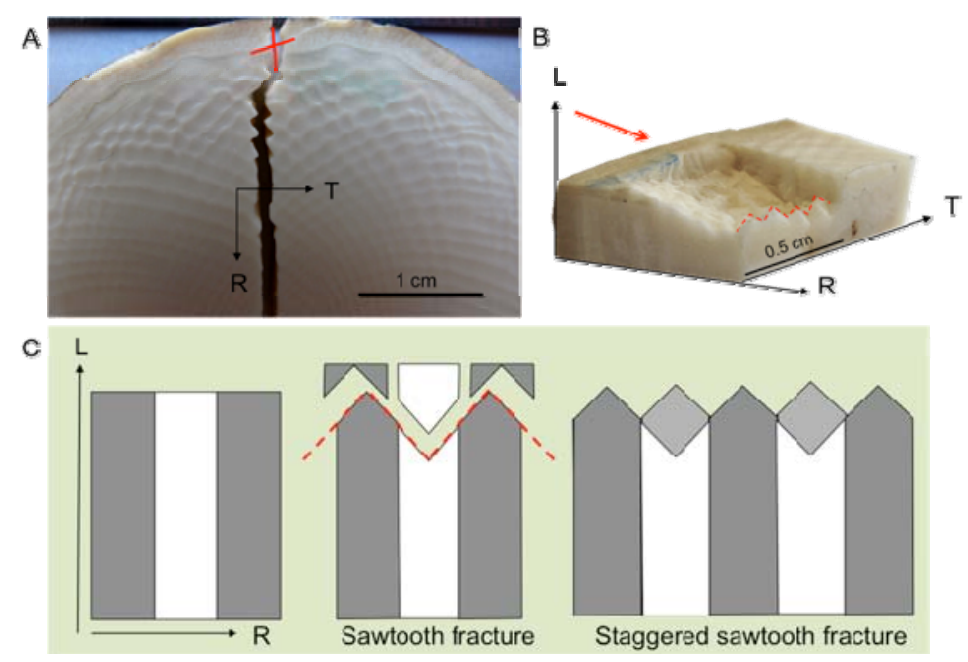

Supplementary Fig. 8. Zizag-like fractures obtained when the percussion was done perpendicular to A) the (RT) plane and B) the (RT) plane. C) Scheme of the possible crack propagation when the percussion is done perpendicular to the tusk axis leading to the sawtooth fracture described in [6].

[1] A. Gourrier, W. Wagermaier, M. Burghammer, D. Lammie, H.S. Gupta, P. Fratzl, C. Riekel, T.J. Wess, O. Paris, Scanning X-ray imaging with small-angle scattering contrast, J. Appl. Crystallogr. 40 (2007) S78-S82.

[2] Y.F. Liu, I. Manjubala, P. Roschger, H. Schell, G.N. Duda, P. Fratzl, Mineral crystal alignment in mineralized fracture callus determined by 3D small-angle X-ray scattering, in: G. Ungar (Ed.), Xiv International Conference on Small-Angle Scattering, Iop Publishing Ltd, Bristol, 2010.

[3] P. Fratzl, N. Fratzlzelman, K. Klaushofer, G. Vogl, K. Koller, Nucleation and growth of mineral crystals in bone studied by small-angle X-ray-scattering, Calcif. Tissue Int. 48(6) (1991) 407-413.

[4] P. Fratzl, M. Groschner, G. Vogl, H. Plenk, J. Eschberger, N. Fratzlzelman, K. Koller, K. Klaushofer, Mineral crystals in calcified tissues - a comparative-study by SAXS, J. Bone Miner. Res. 7(3) (1992) 329-334.

[5] X.W. Su, F.Z. Cui, Hierarchical structure of ivory: from nanometer to centimeter, Mater. Sci. Eng. CBiomimetic Supramol. Syst. 7(1) (1999) 19-29.

[6] C.E. Heckel, S. Wolf, Ivory debitage by fracture in the Aurignacian: experimental and archaeological examples, Journal of Archaeological Science 42 (2014) 1-14. 